\title{
Simulating organic species with the global atmospheric chemistry general circulation model ECHAM5/MESSy1: a comparison of model results with observations
}

\author{
A. Pozzer, P. Jöckel, H. Tost, R. Sander, L. Ganzeveld, A. Kerkweg, and J. Lelieveld \\ Air Chemistry Department, Max-Planck Institute of Chemistry, P.O. Box 3060, 55020 Mainz, Germany \\ Received: 24 November 2006 - Published in Atmos. Chem. Phys. Discuss.: 10 January 2007 \\ Revised: 16 April 2007 - Accepted: 17 April 2007 - Published: 15 May 2007
}

\begin{abstract}
The atmospheric-chemistry general circulation model ECHAM5/MESSy1 is evaluated with observations of different organic ozone precursors. This study continues a prior analysis which focused primarily on the representation of atmospheric dynamics and ozone. We use the results of the same reference simulation and apply a statistical analysis using data from numerous field campaigns. The results serve as a basis for future improvements of the model system. ECHAM5/MESSy1 generally reproduces the spatial distribution and the seasonal cycle of carbon monoxide (CO) very well. However, for the background in the Northern Hemisphere we obtain a negative bias (mainly due to an underestimation of emissions from fossil fuel combustion), and in the high latitude Southern Hemisphere a yet unexplained positive bias. The model results agree well with observations of alkanes, whereas severe problems in the simulation of alkenes and isoprene are present. For oxygenated compounds the results are ambiguous: The model results are in good agreement with observations of formaldehyde, but systematic biases are present for methanol and acetone. The discrepancies between the model results and the observations are explained (partly) by means of sensitivity studies.
\end{abstract}

\section{Introduction}

Ozone chemistry in the troposphere is highly dependent on precursor species like $\mathrm{NO}_{\mathrm{x}}\left(=\mathrm{NO}+\mathrm{NO}_{2}\right), \mathrm{CO}$, methane and non-methane hydrocarbons (NMHC). These trace gases not only play an important role in ozone formation but they also control hydroxyl radicals $\mathrm{HO}_{\mathrm{x}}\left(=\mathrm{OH}+\mathrm{HO}_{2}\right)$ through many complex reaction cycles (Atkinson, 2000; Logan, 1985; Houweling et al., 1998; Seinfeld and Pandis, 1997). Their reactions are strongly interconnected, and the lifetimes of the

Correspondence to: A. Pozzer

(pozzer@mpch-mainz.mpg.de) trace gases range from seconds to years. Three-dimensional (3-D) global models which calculate both transport and chemistry are required to study and/or predict the distribution and the temporal development of these species. The evaluation of such 3-D global models is a necessary task to confirm the correct performance of the model, and different evaluation studies focusing on NMHC have been published (Wang et al., 1998a; Hauglustaine et al., 1998; Poisson et al., 2000; Bey et al., 2001; Horowitz et al., 2003; von Kuhlmann et al., 2003b; Folberth et al., 2006).

Here we evaluate ECHAM5/MESSy1 (further denoted as E5/M1) with data from numerous field campaigns and measurement stations, focusing on CO and NMHCs, notably alkanes, alkenes, and a selection of oxygenated compounds.

After a brief introduction of the model setup and the observational datasets (Sect. 2), we present an overview of the reference simulation and the ability of the model to reproduce the observations (Sect. 3). A more detailed analyses of specific species (Sects. 4 to 7) follows. In the course of our analyses we deduce several hypotheses to explain the discrepancies between our model results and the observations. These hypotheses are subject of sensitivity studies, which we discuss (Sect. 8) as a basis of our conclusions (Sect. 9).

\section{Model and observations}

\subsection{Model description and setup}

E5/M1 is a combination of the general circulation model ECHAM5 (Roeckner et al., 2006) (version 5.3.01) and the Modular Earth Submodel System (MESSy, version 1.1). The implementation follows the MESSy standard (Jöckel et al., 2005). A first description and evaluation of the model system has recently been published (Jöckel et al., 2006). More details about the model system can be found

Published by Copernicus GmbH on behalf of the European Geosciences Union. 
at http://www.messy-interface.org, where a comprehensive description of the model is provided.

The results evaluated here are from the reference simulation $S 1$, as described by Jöckel et al. (2006). The simulation period covers almost 8 years from January 1998 to October 2005. For our analysis we are focusing on the year 2000 , which is expected to be represented by the model with the highest consistency, mainly because the chosen emission setup of primarily emitted species was compiled for this year. We applied the anthropogenic emissions from the EDGAR database (version 3.2 "fast-track", van Aardenne et al. (2005)) for the year 2000 as described by Ganzeveld et al. (2006). The biogenic emissions of organic species have been compiled following Guenther et al. (1995) and are offline prescribed in the model (Ganzeveld et al., 2006) with the unique exception of isoprene, for which the emission is calculated on-line (Kerkweg et al., 2006b). A table resuming the emissions is presented in the electronic supplement of this paper (http://www.atmos-chem-phys.net/ 7/2527/2007/acp-7-2527-2007-supplement.pdf). Dry and wet deposition processes have been extensively described by Kerkweg et al. (2006a) and Tost et al. (2006a), respectively, while the emission procedure has been explained by Kerkweg et al. (2006b). The chemistry is calculated with the MECCA submodel by Sander et al. (2005): The chemical mechanism includes not only the standard $\mathrm{CH}_{4}-\mathrm{CO}-\mathrm{HO}_{\mathrm{x}}-\mathrm{NO}_{\mathrm{x}}$ background chemistry but also the oxidation of non-methane-hydrocarbons (NMHCs) up to isoprene, (see the electronic supplement of Jöckel et al., 2006, http://www.atmos-chem-phys.net/6/5067/2006/ acp-6-5067-2006-supplement.zip in the same special issue).

The applied spectral resolution of the ECHAM5 base model is T42, corresponding to a horizontal resolution of the quadratic Gaussian grid of $\approx 2.8^{\circ} \times 2.8^{\circ}$. The applied vertical resolution is 90 layers (reaching up to $0.01 \mathrm{hPa}$ in the middle of the uppermost layer) of which about 25 are located in the troposphere. No artificial boundary conditions are assumed at the tropopause and the same chemical scheme has been applied troughout the model atmosphere. The model setup includes feedbacks between chemistry and dynamics via the radiation calculations.

The model dynamics has been nudged in the free troposphere (Jeuken et al., 1996; Jöckel et al., 2006; Lelieveld et al., 2007) towards the analysis data of the ECMWF operational model (up to $100 \mathrm{hPa}$ ) in order to represent the realistic meteorology in the troposphere. The nudging is weak enough to not deteriorate the self-consistent model dynamics, but still allows a direct comparison of the model results with observations.

\subsection{Observations}

For our comparison we applied two types of data sets: aircraft and surface measurements. Although the aircraft measurements (Emmons et al., 2000) cover only limited periods, they provide valuable information about the vertical distribution of the analysed trace gases. The surface measurements consist of a large number of multi-year surface observations collected from the literature (Solberg et al., 1996). They, in contrast to the aircraft observations, have limited spatial extension, though they cover an entire (climatological) year and are well suited for the analysis of the seasonal cycle. An additional important global dataset of surface measurements is the NOAA/CMDL flask network (Novelli et al., 1998), which encompasses multiple years of $\mathrm{CO}$ measurements.

Both dataset types are important for a meaningful evaluation of the model. The aircraft measurements are compared only with the year 2000 of the model simulation, sampled in the same area and time period of the observations. The surface measurements are compared with climatological monthly averages of the model results, sampled at the lowest level of the terrain following vertical hybrid-pressure systems. The NOAA/CMDL flask measurements are compared with model calculated monthly averages.

For a quantitative statistical analysis, correlations between the model results and the aircraft observations are calculated with respect to the altitude, while the correlations between the model results and the surface measurements are calculated with respect to time.

\section{Overview of the results}

To first provide an overview of the overall model performance regarding important $\mathrm{O}_{3}$ precursors, we statistically compare model results and observations of the following species: alkanes and alkenes with up to three carbon atoms, oxygenated compounds (methanol, acetone, formaldehyde, acetaldehyde), hydroperoxide and isoprene. Aircraft observations are additionally compared to model results for methane, ozone and nitric acid.

\subsection{Aircraft measurements}

Table 1 summarises the comparison of E5/M1 model results with aircraft measurements. Figure 1 depicts the corresponding Taylor diagram, visualising the quality of the simulation for several tracers in a single diagram. It shows the correlation coefficient between model results and observations $(R)$ by the angle to the ordinate. The standard deviation of the model normalised to the standard deviation of the observations $\left(\sigma_{\text {model }} / \sigma_{\text {obs }}\right)$ is the distance from the origin. The observations are therefore located at a correlation of 1 and a normalised standard deviation of 1 . The distance between a a point and this "ideal" point is the centered pattern root mean square. The better a model reproduces the observations, the closer are the resulting points located to this "ideal" point. A detailed explanation of this diagram has been presented by Taylor (2001). 
Table 1. Summary of the correlation coefficients $(R)$ and linear regression analyses of model results versus aircraft observations (model $=m \times$ measurement $+b$ ). Bias and $b$ are in $\mathrm{pmol} / \mathrm{mol}$; bias $=$ model results minus observations.

\begin{tabular}{lccccc}
\hline trace gas & num. obs. & bias & $m$ & $b$ & $R^{2}$ \\
\hline $\mathrm{C}_{2} \mathrm{H}_{4}$ & 454 & -23.87 & 0.26 & 9.975 & 0.409 \\
$\mathrm{C}_{2} \mathrm{H}_{6}$ & 473 & -174.03 & 0.69 & 78.692 & 0.799 \\
$\mathrm{C}_{3} \mathrm{H}_{6}$ & 332 & -11.50 & 0.14 & 0.267 & 0.410 \\
$\mathrm{C}_{3} \mathrm{H}_{8}$ & 472 & -18.82 & 0.92 & -5.755 & 0.768 \\
$\mathrm{CH}_{3} \mathrm{COCH}$ & 246 & -376.85 & 0.42 & -28.717 & 0.385 \\
$\mathrm{CH}_{3} \mathrm{OH}$ & 116 & -447.82 & 0.18 & 255.18 & 0.313 \\
$\mathrm{CH}_{3} \mathrm{OOH}$ & 366 & -13.19 & 0.71 & 94.598 & 0.718 \\
$\mathrm{HCHO}$ & 213 & 6.41 & 0.74 & 55.786 & 0.631 \\
$\mathrm{H}_{2} \mathrm{O}_{2}$ & 411 & 3.73 & 0.63 & 275.81 & 0.552 \\
$\mathrm{HNO}_{3}$ & 416 & -13.05 & 0.53 & 63.115 & 0.337 \\
$\mathrm{O}_{3}$ & 506 & 11835 & 1.78 & -28464 & 0.544 \\
$\mathrm{PAN}_{\mathrm{CO}}$ & 395 & 141.97 & 0.71 & 188.99 & 0.268 \\
$\mathrm{CH}_{4}$ & 456 & -8621.8 & 0.51 & 36381 & 0.633 \\
\hline
\end{tabular}

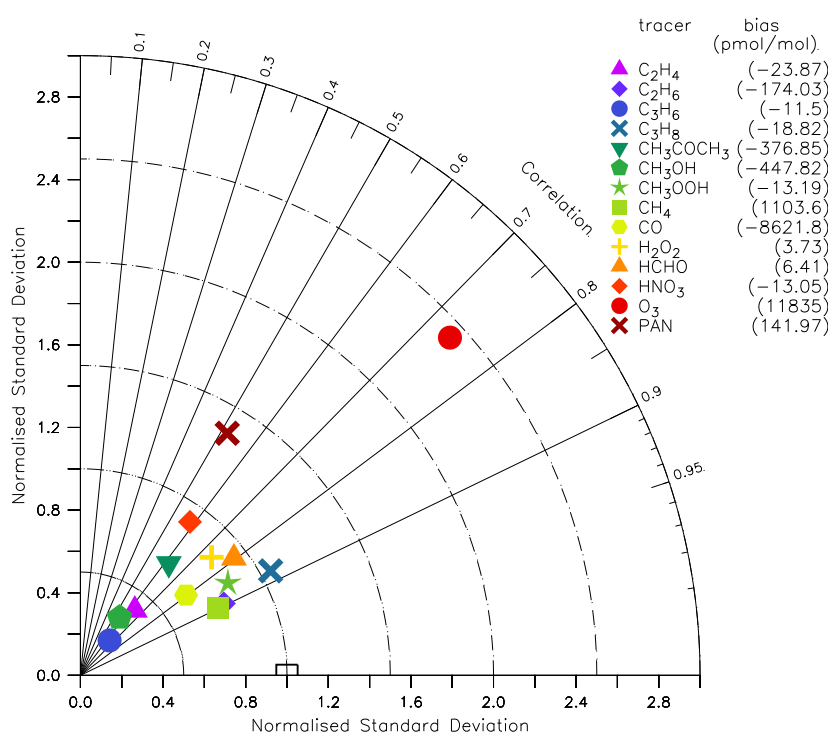

Fig. 1. Taylor diagram of the comparison between aircraft measurements and simulation $S 1$. The biases are presented in parentheses (in $\mathrm{pmol} / \mathrm{mol}$ ). The empty box represents the measurements.

Correlations and biases have been also calculated using an "uncertainties" weight, maintaining the relationship between the three statistical quantities visualised in the Taylor diagram. The uncertainties weight is calculated as the square root of the sum of "model variability" squared and "measurement variability" squared. The model variability is the standard deviation from the averaged output values, and the measurement variability is a combination of instrumental errors and standard deviation. We refer to Jöckel et al. (2006,
Table 2. Correlation coefficients and linear regression analyses between the model results and the aircraft observations, both weighted with relative uncertainties (bias $=$ model results minus observations).

\begin{tabular}{lcccc}
\hline trace gas & num. obs. & bias $^{1}$ & bias $^{1}$ & $R^{2}$ \\
\hline $\mathrm{C}_{2} \mathrm{H}_{4}$ & 454 & -13.37 & -921.3 & 0.624 \\
$\mathrm{C}_{2} \mathrm{H}_{6}$ & 473 & -0.76 & -196.57 & 0.948 \\
$\mathrm{C}_{3} \mathrm{H}_{6}$ & 332 & -4818.76 & -78982 & 0.996 \\
$\mathrm{C}_{3} \mathrm{H}_{8}$ & 472 & -0.49 & -55.21 & 0.985 \\
$\mathrm{CH}_{3} \mathrm{COCH}$ & 246 & -3.46 & -648.6 & 0.767 \\
$\mathrm{CH}_{3} \mathrm{OH}$ & 116 & -2.03 & -724.54 & 0.599 \\
$\mathrm{CH}_{3} \mathrm{OOH}$ & 366 & 0.05 & 10.72 & 0.941 \\
$\mathrm{HCHO}$ & 213 & 0.20 & 32.00 & 0.760 \\
$\mathrm{H}_{2} \mathrm{O}_{2}$ & 411 & 0.07 & 36.977 & 0.944 \\
$\mathrm{HNO}_{3}$ & 416 & -0.15 & -28.12 & 0.767 \\
$\mathrm{O}_{3}$ & 506 & 0.14 & 3141.2 & 0.487 \\
$\mathrm{PAN}_{\mathrm{CO}}$ & 395 & 1.17 & 205.08 & 0.999 \\
$\mathrm{CH}_{4}$ & 456 & -0.10 & -2692.2 & 0.818 \\
\hline
\end{tabular}

$1_{\text {in units of standard deviation }}$

Appendix D), for a detailed explanation of these calculations.

With this approach, the locations with high variability have less weight. This allows us to compare values which are more representative for the average conditions and to eliminate specific episodes that cannot be expected to be reproduced by the model. The results of this recalculation are shown in Fig. 2 and listed in Table 2.

According to this analysis, the discrepancies between model results and measurements are smaller than the uncertainties, if the absolute value of the weighted bias (i.e., in units of the normalised standard deviation, Fig. 2 and Table 2) for a specific tracer is less than one. A high weighted correlation in combination with a weighted bias lower than one indicates that the model is able to reproduce the observed mixing ratios on average. This is not the case for $\mathrm{C}_{2} \mathrm{H}_{4}, \mathrm{C}_{3} \mathrm{H}_{6}, \mathrm{CH}_{3} \mathrm{COCH}_{3}, \mathrm{CH}_{3} \mathrm{OH}$ and PAN. $\mathrm{C}_{3} \mathrm{H}_{6}$ and $\mathrm{CH}_{3} \mathrm{OH}$ are not even shown in Fig. 2; due to their very high normalised standard deviations they are outside the shown range. The inability of the model to reproduce the vertical distribution of these compounds, as indicated by the relatively low correlation with all aircraft measurements included in the database, requires a more detailed analysis. This will be conducted in Sect. 8 .

\subsection{Surface measurements}

Figures 3-4 and Tables 3-4 summarise the comparison between the model simulation (climatological monthly 


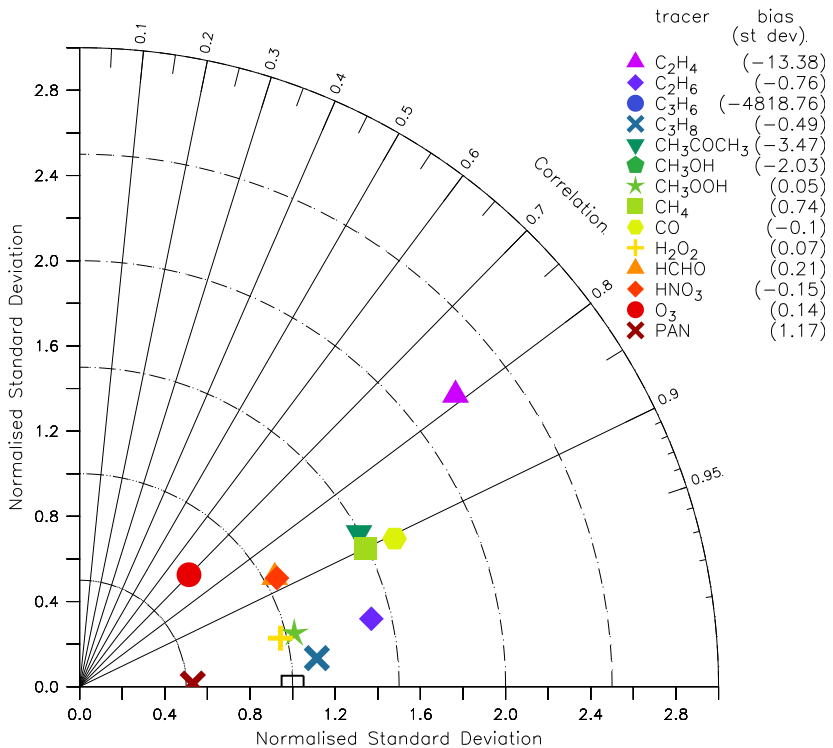

Fig. 2. Taylor diagram of the comparison between aircraft measurements and model results, both weighted with relative uncertainties (Jöckel et al., 2006). The biases are listed in parentheses (units of standard deviation). The empty box represents the measurements.

Table 3. Summary of the correlation coefficients and linear regression analyses of model results versus station observations (model $=$ $m \times$ measurement $+b$ ). Bias and $b$ are in nmol $/ \mathrm{mol}$; bias $=$ model results minus observations.

\begin{tabular}{lccccc}
\hline trace gas & num. obs. & bias & $\mathrm{m}$ & $\mathrm{b}$ & $R^{2}$ \\
\hline $\mathrm{C}_{2} \mathrm{H}_{4}$ & 138 & 0.20 & 0.534 & 0.504 & 0.396 \\
$\mathrm{C}_{2} \mathrm{H}_{6}$ & 150 & 0.24 & 0.828 & 0.544 & 0.539 \\
$\mathrm{C}_{3} \mathrm{H}_{6}$ & 137 & 0.01 & 0.658 & 0.060 & 0.502 \\
$\mathrm{C}_{3} \mathrm{H}_{8}$ & 150 & 0.61 & 1.130 & 0.508 & 0.424 \\
$\mathrm{CH}_{3} \mathrm{CHO}$ & 77 & 0.15 & 0.197 & 0.582 & 0.082 \\
$\mathrm{CH}_{3} \mathrm{COCH}$ & 81 & -0.08 & 0.528 & 0.459 & 0.508 \\
$\mathrm{HCHO}$ & 65 & -0.11 & 0.470 & 0.495 & 0.553 \\
$\mathrm{PAN}$ & 48 & 0.34 & 1.809 & 0.190 & 0.538 \\
$\mathrm{CO}^{1}$ & 4224 & 5.675 & 0.976 & 6.499 & 0.672 \\
\hline
\end{tabular}

${ }^{1}$ from NOAA/CMDL flask network (see Sect. 4)

averages of the 7 years 1998-2004) and the climatology derived from the station measurements.

As can be seen in Fig. 3 and Table 3, the model generally overestimates the mixing ratios of these trace gases at the surface, with the exception of acetone $\left(\mathrm{CH}_{3} \mathrm{COCH}_{3}\right)$ and formaldehyde (HCHO). As further shown in Fig. 4 and Table 4 , only the biases of ethene $\left(\mathrm{C}_{2} \mathrm{H}_{4}\right)$, propene $\left(\mathrm{C}_{3} \mathrm{H}_{6}\right)$ and PAN exceed one normalised standard deviation, and consequently the discrepancy between the model results and the observations cannot be explained by the model variability

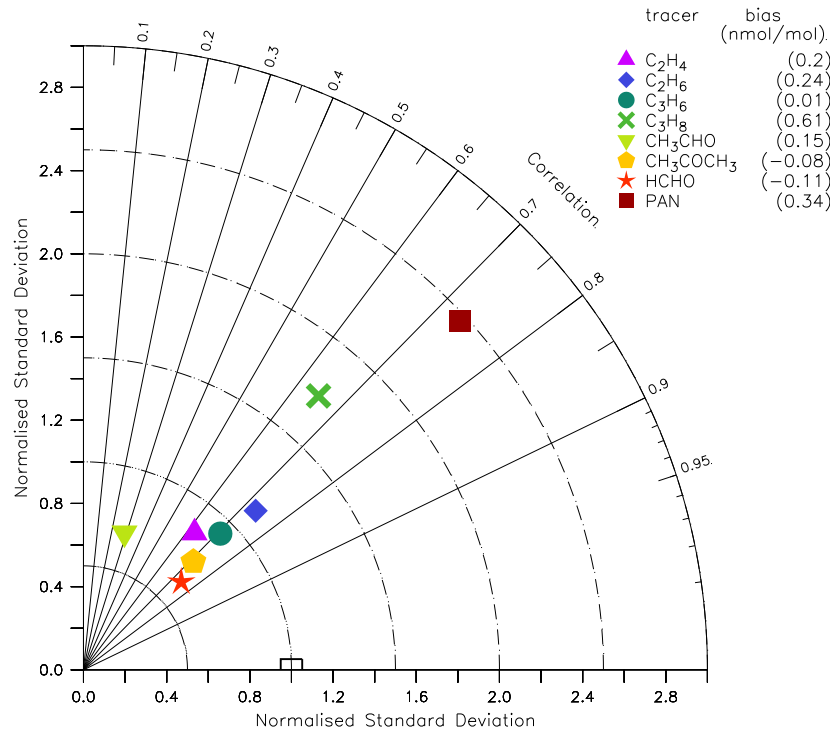

Fig. 3. Taylor diagram of the comparison between station observations and model results. The biases are presented in parentheses (in $\mathrm{pmol} / \mathrm{mol}$ ). The empty box represents the measurements.

Table 4. Correlation coefficients and linear regression analyses between the model results and the station observations, both weighted with relative uncertainties (bias $=$ model results minus observations).

\begin{tabular}{lcccc}
\hline trace gas & num. obs. & bias $^{1}$ & bias $^{2}$ & $R^{2}$ \\
\hline $\mathrm{C}_{2} \mathrm{H}_{4}$ & 138 & 2.67 & 0.342 & 0.986 \\
$\mathrm{C}_{2} \mathrm{H}_{6}$ & 150 & -0.22 & -0.043 & 0.996 \\
$\mathrm{C}_{3} \mathrm{H}_{6}$ & 137 & -6.18 & -0.149 & 0.890 \\
$\mathrm{C}_{3} \mathrm{H}_{8}$ & 150 & -0.17 & -0.031 & 0.999 \\
$\mathrm{CH}_{3} \mathrm{CHO}$ & 77 & 0.76 & 0.080 & 0.298 \\
$\mathrm{CH}_{3} \mathrm{COCH}$ & 81 & -1.01 & -0.106 & 0.737 \\
$\mathrm{HCHO}$ & 65 & -0.93 & -0.125 & 0.898 \\
PAN & 48 & 5.2 & 0.381 & 0.891 \\
\hline
\end{tabular}

$1_{\text {in units of standard deviation }}$

and/or the variability of the observations. Furthermore, Fig. 3 shows that the amplitude of the seasonal cycle is underestimated for many NMHCs, since the absolute value of the normalised standard deviation is lower than 1 . We hence infer that the model is able to reproduce (with the exception of the aforementioned trace gases) the observed magnitude of the tracer mixing ratios and the phase of the seasonal cycle, though with a generally underestimated amplitude.

Nevertheless, the model underestimates NMHCs in comparison to the aircraft measurements (Table 1), mainly in the upper troposphere. Jöckel et al. (2006) showed that the global air-mass weighted average $\mathrm{OH}$ abundance in the 
middle and upper troposphere in the simulation is lower than that calculated by Spivakovsky et al. (2000). This implies that the oxidation reactions are probably not responsible for the underestimation of NMHCs. Rather, there are indications that the convection scheme applied in the model does not sufficiently transport these species to the upper troposphere (Tost, 2006; Tost et al., 2006b).

\section{Carbon monoxide, $\mathrm{CO}$}

Carbon monoxide provides the most important sink for $\mathrm{OH}$ (Lelieveld et al., 2002; Logan et al., 1981; Thompson, 1992). A correct simulation of this tracer is very important for studies of atmospheric oxidants. The emissions of $\mathrm{CO}$ applied in the present simulation have been described by Ganzeveld et al. (2006, and references therein). There are large uncertainties with respect to the amount of $\mathrm{CO}$ globally lost by dry deposition (e.g., 115-230 Tg/yr (Sanhueza et al., 1998), $540 \pm 430 \mathrm{Tg} / \mathrm{yr}$ (Moxley and Cape, 1997), $150 \mathrm{Tg} / \mathrm{yr}$ (von Kuhlmann et al., 2003b)). In a recent study Horowitz et al. (2003) estimated the global dry deposition of CO to be only around $2 \mathrm{Tg} / \mathrm{yr}$. Following this study, in our model simulation the dry deposition of $\mathrm{CO}$ was switched off. Although the simulated $\mathrm{CO}$ will be influenced by taking into account the process of dry deposition, the effect is potentially significant for the budget only in very remote regions. We will investigate this hypothesis further in Sect. 8.

Thanks to the large dataset of $\mathrm{CO}$ observations available from the NOAA/CMDL network (Novelli et al., 1998), a more detailed analysis is possible for $\mathrm{CO}$ than for the other studied trace gases. This allows the direct comparison of 7 years (1998-2004) of monthly averaged model results with the corresponding observations. It cannot be expected that the model simulation fully reproduces the inter-annual variability due to the prescribed climatological emissions for the year 2000. Nevertheless, the meteorological inter-annual variability is included through the applied nudging procedure.

The correlation between the model results and the observations is generally good (see Sect. 3.2) with $R^{2}=0.67$.

As evident in Fig. 5, where data from selected locations are shown, the phase of the seasonal cycle of $\mathrm{CO}$ is well reproduced (e.g., Alert, Canada (ALT), or Mace Head, Ireland (MID)). The Taylor diagram in Fig. 6 completes the picture and confirms the high correlation between the model results and the measurements. The correlation is high at remote locations (south of $60^{\circ} \mathrm{S}$ ) with $R \approx 0.9$, indicating that the main processes controlling the $\mathrm{CO}$ abundance are well represented by the model. However, at locations between $20^{\circ} \mathrm{N}$ and $40^{\circ} \mathrm{N}$ the correlation is lower, because these regions are strongly influenced by local emissions, including industry and biomass burning. Even though the amplitude of the seasonal cycle is well reproduced by the model at some locations (e.g., Mauna Loa, Hawaii, (MLO)), it overall tends

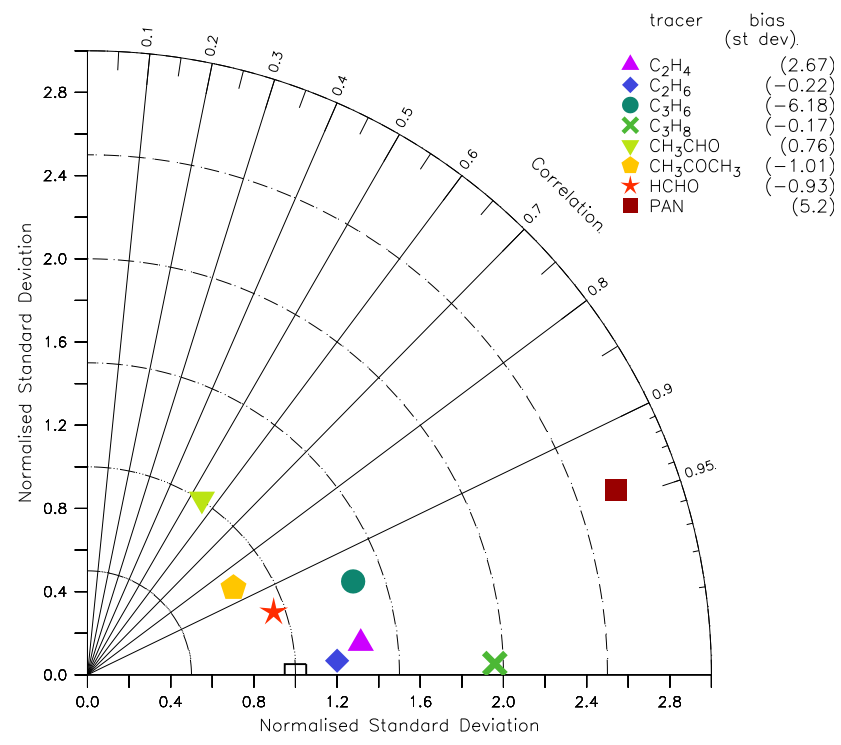

Fig. 4. Taylor diagram of the comparison between station measurements and model results, both weighted with relative uncertainties. The biases are listed in parentheses (units of standard deviation). The empty box represents the measurements.

to be underestimated (see Fig. 6, normalised standard deviation $\leq 1)$. In the Northern Hemisphere (e.g., Zeppelin, (ZEP) or Alert, Canada, (ALT)) the maximum during winter seems to be systematically underestimated.

Looking further at the overall biases of the model simulation compared to the observations, some of the discrepancies between model results and observations can be resolved. Figure 7 depicts the relative biases at all NOAA/CMDL stations. Strong positive biases are present mainly in polluted regions where the model resolution is not sufficient to resolve the details of the source distributions and the meteorology. As pointed out by Haas-Laursea and Hartley (1997), the flask samples have been collected under non-polluted conditions, i.e., for stations close to local sources only certain wind directions have been selected to avoid local contamination. The model results are not filtered in the same way, and at the rather low model grid resolution, local sources are sometimes located in the same grid box as the measurement station. Therefore, the simulated mixing ratios are potentially higher than the observed. Sampling the simulated data one grid-box upwind of the polluted locations, the correlation between model results and observations increases drastically and the overestimation by the model almost disappears (Fig. 5).

In contrast to polluted regions, the model tends to underestimate CO compared to observations in remote regions of the Northern Hemisphere (Fig. 7). This can probably be attributed to underestimated anthropogenic emissions, which relatively strongly influence the background mixing ratio in the Northern Hemisphere. In fact, in the present simulation, 
Table 5. Budget of different trace gases in the E5/M1 simulation (this work) compared to previous studies.

\begin{tabular}{|c|c|c|c|c|c|c|c|}
\hline tracer & $\begin{array}{l}\text { emission } \\
(\mathrm{Tg} / \mathrm{yr}) \\
\text { this work }\end{array}$ & $\begin{array}{l}\text { emission } \\
(\mathrm{Tg} / \mathrm{yr}) \\
\text { literature }\end{array}$ & $\begin{array}{c}\text { dry deposition } \\
(\mathrm{Tg} / \mathrm{yr}) \\
\text { this work }\end{array}$ & $\begin{array}{c}\text { dry deposition } \\
(\mathrm{Tg} / \mathrm{yr}) \\
\text { literature }\end{array}$ & $\begin{array}{c}\text { wet deposition } \\
(\mathrm{Tg} / \mathrm{yr}) \\
\text { this work }\end{array}$ & $\begin{array}{c}\text { wet deposition } \\
(\mathrm{Tg} / \mathrm{yr}) \\
\text { literature }\end{array}$ & $\begin{array}{c}\text { burden }(\mathrm{Tg}) \\
\text { annual average } \\
\text { this work }\end{array}$ \\
\hline $\mathrm{C}_{2} \mathrm{H}_{4}$ & 26.35 & $19.55^{\mathrm{h}}-22.35^{\mathrm{f}}$ & - & - & - & - & 0.12 \\
\hline $\mathrm{C}_{2} \mathrm{H}_{6}$ & 12.46 & $11.95^{\mathrm{f}}-12.26^{\mathrm{h}}$ & - & - & - & - & 2.51 \\
\hline $\mathrm{C}_{3} \mathrm{H}_{6}$ & 9.92 & $6.95^{\mathrm{h}}-9.87^{\mathrm{f}}$ & - & - & - & - & 0.01 \\
\hline $\mathrm{C}_{3} \mathrm{H}_{8}$ & 11.97 & $10.18^{\mathrm{f}}-13.46^{\mathrm{b}}$ & - & - & - & - & 0.66 \\
\hline $\mathrm{CH}_{3} \mathrm{COCH}_{3}$ & 47.96 & $\begin{array}{c}95^{\mathrm{i}} \\
80.16^{\mathrm{h}} \\
59.64^{\mathrm{f}} \\
46.07^{\mathrm{g}}\end{array}$ & 24.48 & $\begin{array}{c}12.96^{\mathrm{a}} \\
9^{\mathrm{b}} \\
8.8^{\mathrm{e}}\end{array}$ & - & - & 2.23 \\
\hline $\mathrm{CH}_{3} \mathrm{OH}$ & 77.74 & $\begin{array}{l}312^{\mathrm{f}} \\
240^{\mathrm{c}} \\
128^{\mathrm{d}}\end{array}$ & 42.16 & $\begin{array}{c}31.35^{\mathrm{a}} \\
55^{\mathrm{c}}\end{array}$ & - & $12^{\mathrm{c}}$ & 2.46 \\
\hline HCHO & 7.78 & $6.97^{\mathrm{f}}$ & 43.35 & $45.73^{\mathrm{a}}$ & 1.74 & $31.62^{\mathrm{a}}$ & 1.05 \\
\hline $\mathrm{H}_{2} \mathrm{O}_{2}$ & - & - & 142.12 & $170.70^{\mathrm{a}}$ & 194.22 & $244.52^{\mathrm{a}}$ & 4.07 \\
\hline $\mathrm{CO}$ & \multicolumn{2}{|c|}{ see Table 6} & \multicolumn{2}{|c|}{ see Sect. 8} & - & - & 375.93 \\
\hline
\end{tabular}

${ }^{a}$ von Kuhlmann et al. (2003b)

b Jacob et al. (2002)

${ }^{\mathrm{c}} \mathrm{Jacob}$ et al. (2005)

${ }^{\mathrm{d}}$ Heikes et al. (2002)

e Arnold et al. (2005)

${ }^{\mathrm{f}}$ Horowitz et al. (2003)

g Park et al. (2004a)

${ }^{\mathrm{h}}$ Folberth et al. (2006)

${ }^{\mathrm{i}}$ Jacob et al. (2002), only terrestrial

as shown in Table 6, $\mathrm{CO}$ emissions from fossil fuel usage are at the lower end of the range of estimates in the literature.

In the Southern Hemisphere the model simulation produces higher mixing ratios of $\mathrm{CO}$ than observed (Fig. 7). This is particularly evident for locations south of $50^{\circ} \mathrm{S}$. This significant bias is especially visible in Fig. 5, for Palmer station, Antarctic (PSA), and Halley Bay, Antarctic (HBA). This discrepancy is present in many other models (Hauglustaine et al., 1998; Wang et al., 1998b; Bey et al., 2001; von Kuhlmann et al., 2003b; Horowitz et al., 2003; Park et al., 2004b; Folberth et al., 2006) and unexplained so far.

The hypothesis of underestimated emissions in polluted regions (i.e., primarily from fossil fuel usage) is supported by the analysis of the vertical profiles from the aircraft observations. Figure 8 (TRACE-P, China or PEM-WEST-B, China) shows that $\mathrm{CO}$ is clearly underestimated near China, especially in the planetary boundary layer, where the influence of the emissions is largest. This underestimation is also present further downwind (PEM-WEST-B, Philippine Sea, TRACE$\mathrm{P}$, Guam), however, it almost disappears in the central Pacific region (TRACE-P, Hawaii). Interestingly, the correct representation of carbon monoxide in East Asia is a prob- lem for many atmospheric chemistry models. Kiley et al. (2003) demonstrated that many models are underestimating $\mathrm{CO}$ in the western Pacific region. Wang et al. (2004, and references therein) performed an inverse modelling analysis and calculated that an increase of the $\mathrm{CO}$ emissions in East Asia of around $45 \%$ from the a priori estimate (Streets et al., 2003) is required to match the observations. More recently, Streets et al. (2006) estimated $116 \mathrm{Tg} / \mathrm{yr}$ for the year 2000 and $157 \mathrm{Tg} / \mathrm{yr}$ for the year 2001 of CO emissions from China with an uncertainty of $68 \%$.

\section{Non-methane hydrocarbons}

Comparison of the simulated non-methane hydrocarbon mixing ratios with observations yields a dual picture (see Sect. 3). Some of the simulated trace gases are in particularly good agreement with the measurements (e.g., propane $\left(\mathrm{C}_{3} \mathrm{H}_{8}\right)$ ), while others are largely uncorrelated with measurements (e.g., ethene $\left(\mathrm{C}_{2} \mathrm{H}_{4}\right)$ and propene $\left.\left(\mathrm{C}_{3} \mathrm{H}_{6}\right)\right)$. In the case of $\mathrm{C}_{3} \mathrm{H}_{6}$, the simulation does not reproduce the observed profiles. The simulated values are completely out of range of the 

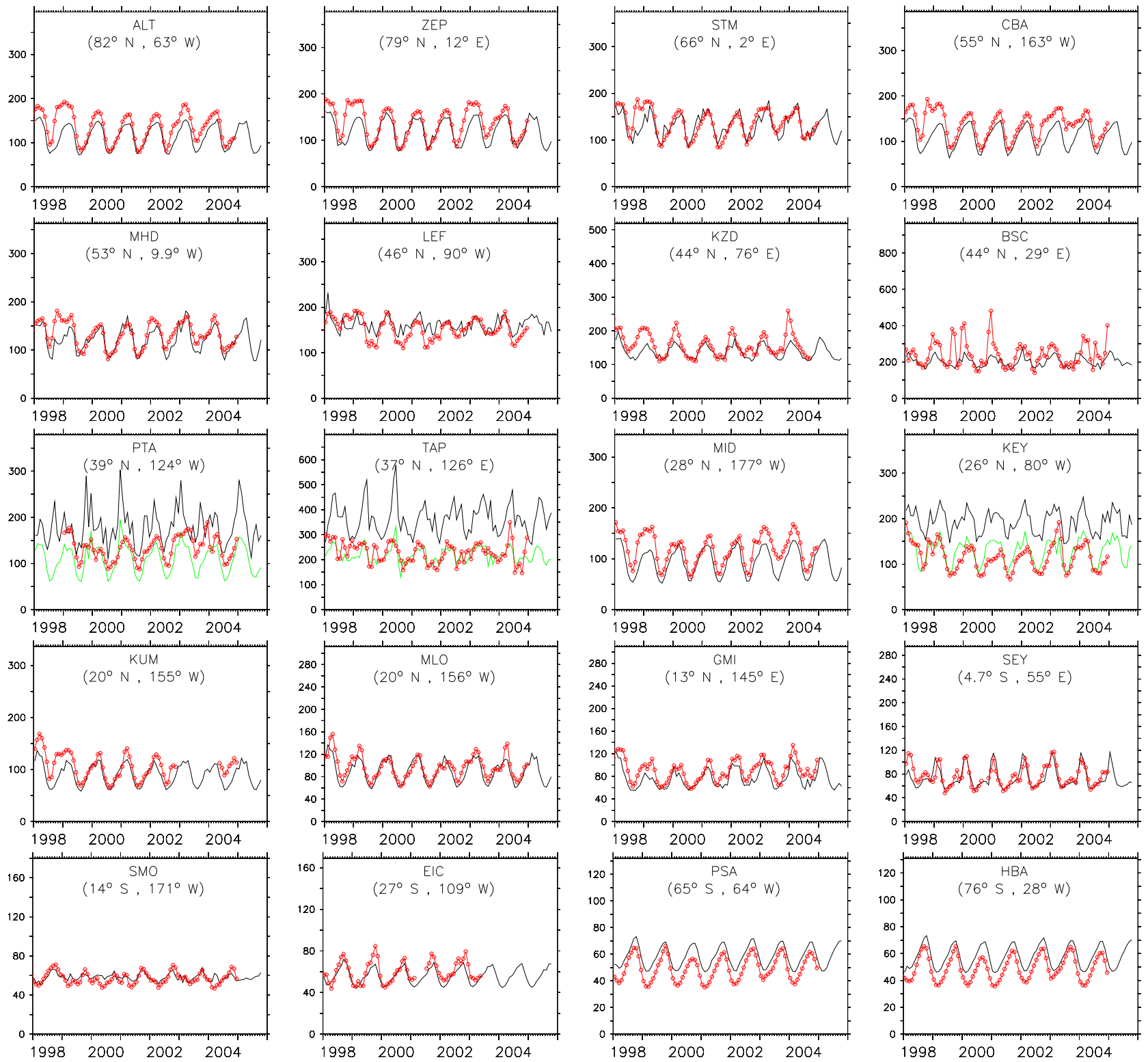

Fig. 5. Comparison of simulated (black) and observed (red, Novelli et al. (1998)) CO mixing ratios in nmol/mol (ordered by latitude). The green lines show the model results sampled from the corresponding grid-boxes upwind (see text).

Table 6. Different estimates of CO emissions in $\mathrm{Tg} / \mathrm{yr}$. The total includes also other sources (e.g. biogenic).

\begin{tabular}{|c|c|c|c|c|c|c|}
\hline & Brasseur et al. (1998) & Bey et al. (2001) & von Kuhlmann et al. (2003a) & Park et al. (2004a) & this work & range $^{a}$ \\
\hline Fossil fuel & 281 & 388 & 400 & 384 & 281 & $300-600$ \\
\hline Biomass burning & 661 & 522 & 748 & 746 & 702 & $300-900$ \\
\hline Total & 1218 & 1043 & 1261 & 1131 & 1096 & $656-1730$ \\
\hline
\end{tabular}

${ }^{\mathrm{a}}$ from Bates et al. (1995) 


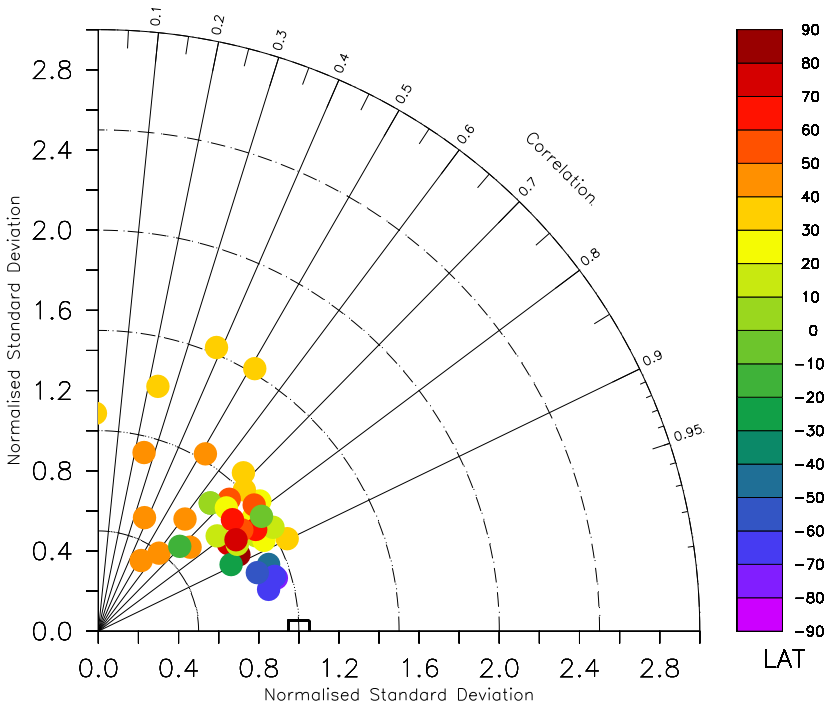

Fig. 6. Taylor diagram comparing 7 year (1998-2004) monthly averages of $\mathrm{CO}$ from the model simulations with the surface observations from the NOAA/CMDL network (Novelli et al., 1998). The colour code denotes the geographic latitude.

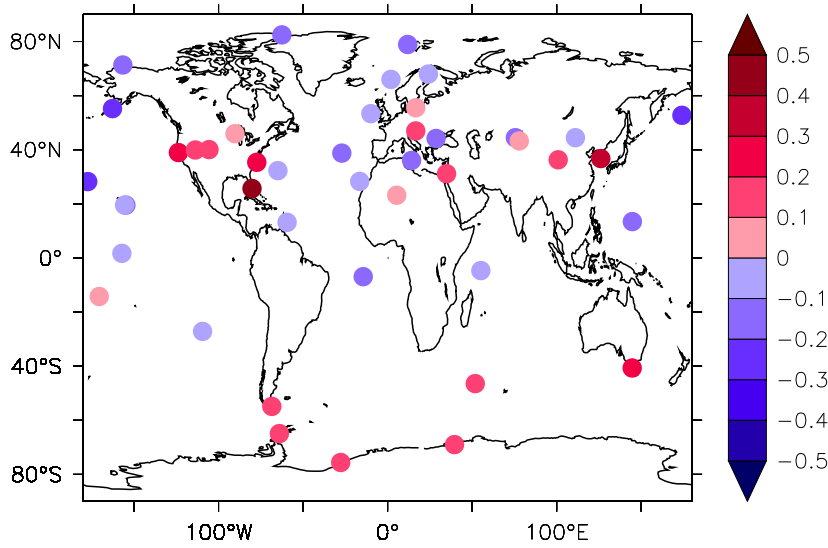

Fig. 7. Relative differences of 7 year averaged $\mathrm{CO}$ between model and measurements ((mod-obs)/mod).

observed values, even including measurement uncertainties and variability (see bias in Sect. 3). Moreover, the simulated and observed vertical profiles are uncorrelated (see Fig. 2), i.e., the model is unable to reproduce the shape of the profiles.

\subsection{Alkanes (ethane $\mathrm{C}_{2} \mathrm{H}_{6}$ and propane $\mathrm{C}_{3} \mathrm{H}_{8}$ )}

Among all considered NMHCs, the alkanes are best reproduced by the model. The overall correlation $\left(R^{2}>0.75\right.$, see Table 1) indicates a very good agreement between these simulated trace gases and the respective observations. Table 2 shows that the model results are well within the range of the measurements.
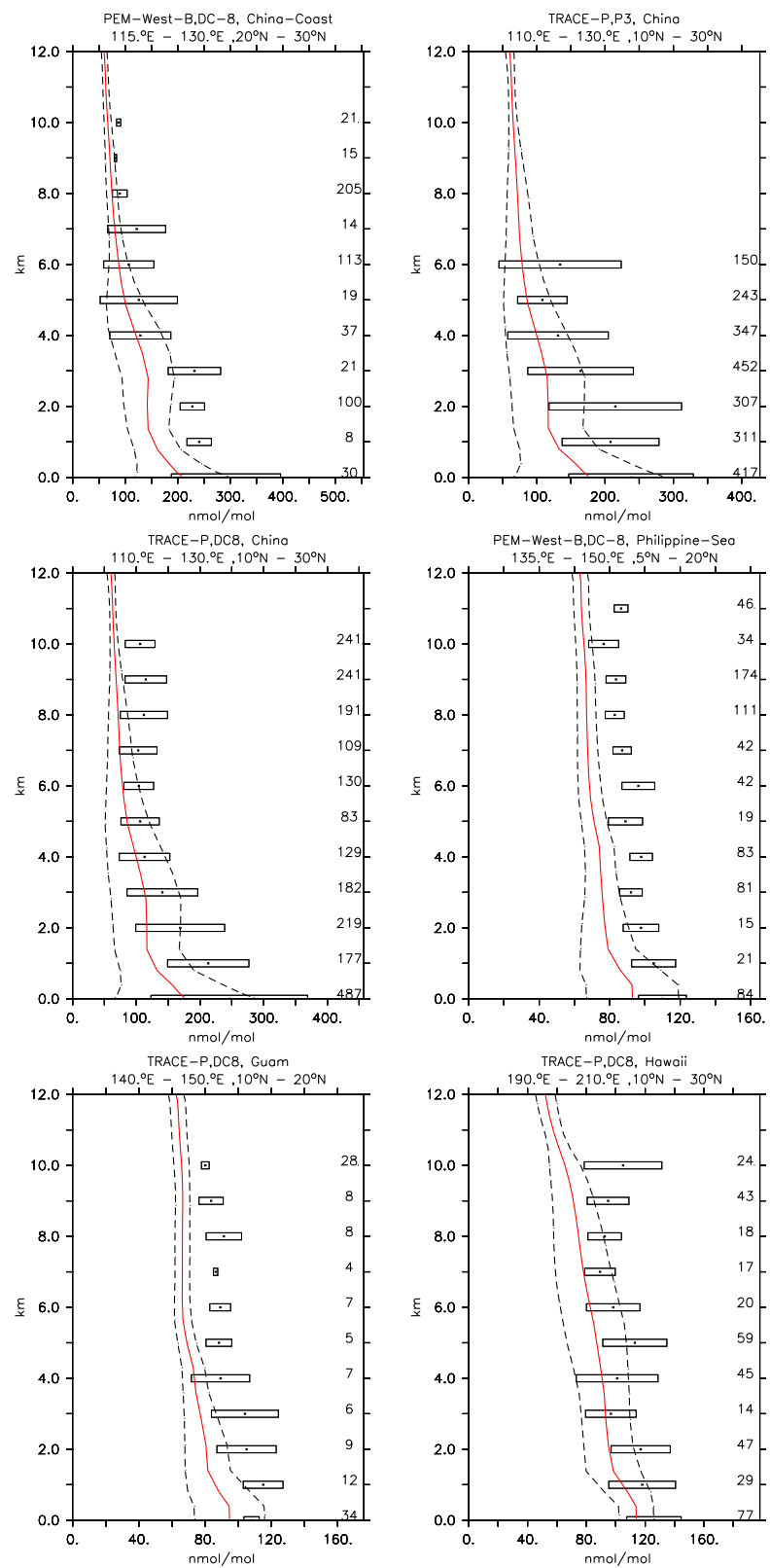

Fig. 8. Vertical profiles of $\mathrm{CO}(\mathrm{nmol} / \mathrm{mol})$ for some selected campaigns from Emmons et al. (2000). Asterisks and boxes represent the average and the standard deviation (w.r.t. space and time) of the measurements in the region, respectively. The simulated average is indicated by the red line and the corresponding simulated standard deviation w.r.t. time and space by the dashed lines. On the right side the number of measurements is listed.

In the case of ethane $\left(R^{2}=0.8\right)$, the improvement compared to von Kuhlmann et al. (2003b, $\left.R^{2}=0.75\right)$ is mainly due to different spatial distribution patterns of the emissions. For example, the total emission of $\mathrm{C}_{2} \mathrm{H}_{6}$ due to biomass burning in E5/M1 (Ganzeveld et al., 2006) is about $0.87 \mathrm{Tg} / \mathrm{yr}$ lower than in von Kuhlmann et al. (2003a), and 

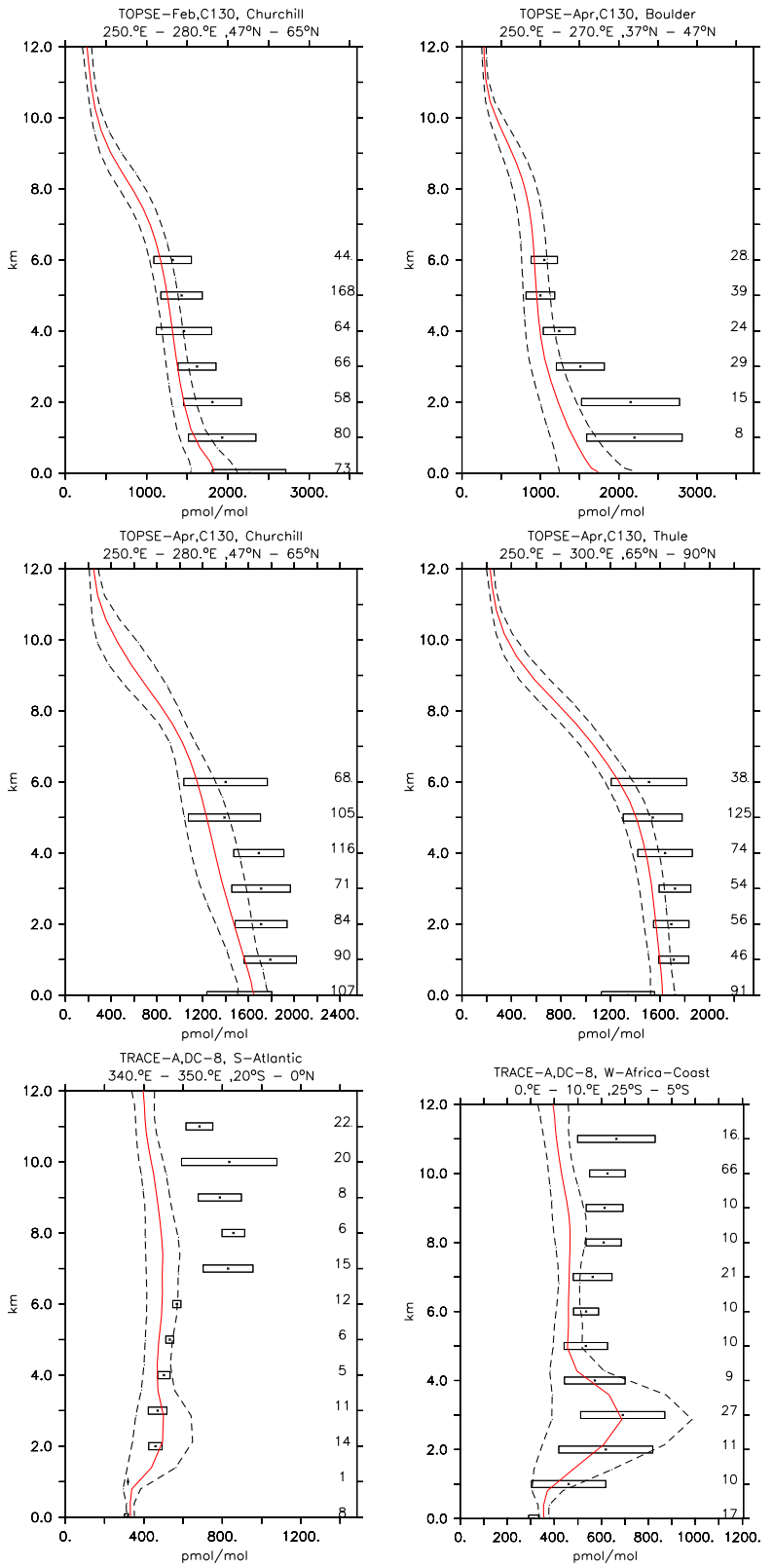

Fig. 9. Vertical profiles of $\mathrm{C}_{2} \mathrm{H}_{6}$ (in pmol/mol) for some selected campaigns. Symbols and colours as in Fig. 8.

the anthropogenic emissions are about $0.75 \mathrm{Tg} / \mathrm{yr}$ higher. Although the total is essentially unchanged, the different distribution improves the quality of the simulation. However, the model simulation is at the lower end of the measurements, especially when compared with the TOPSE campaign (Fig. 9). The anthropogenic emissions in the model, in fact, are not sufficient to perfectly match the observed values. This is clearly visible when the model results are compared to surface measurements (Fig. 10). Ethane is underestimated by the model at the surface in North America (Fraserdale, Lac la Flamme) mainly due to an underestimation of the emissions
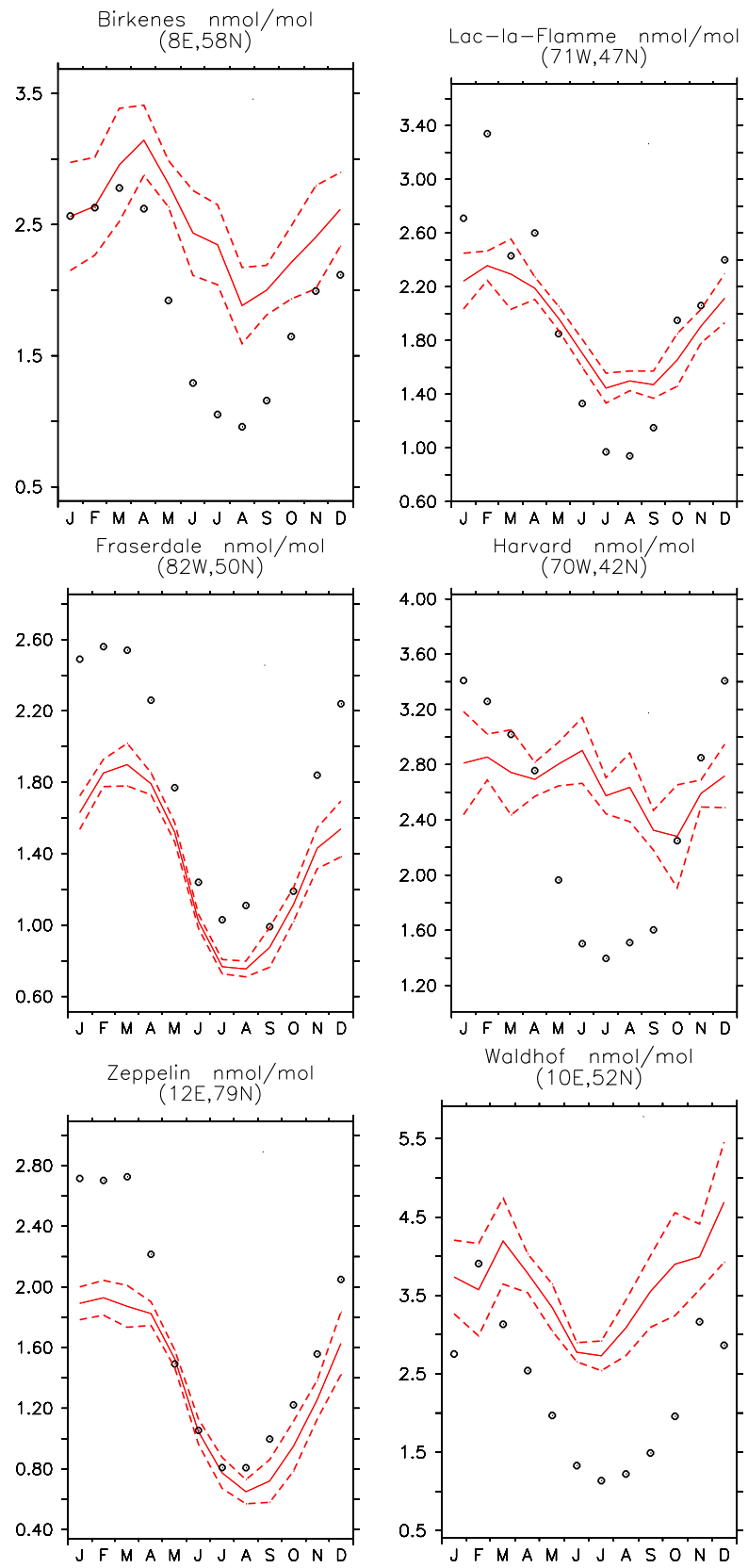

Fig. 10. Seasonal cycle (monthly averages) of $\mathrm{C}_{2} \mathrm{H}_{6}$ (in nmol $/ \mathrm{mol}$ ) for some selected locations at the surface (Solberg et al., 1996). Model: red solid line; model standard deviation: red, dashed line; measurements: circles.

compiled in the EDGAR database (Jacob et al., 2002; Poisson et al., 2000). Furthermore, the amplitude of the seasonal cycle is not well reproduced at these locations, with problems mainly in reproducing the maximum in winter. The simulation reproduces biomass burning plumes observed in the TRACE-A campaign (African coast, Fig. 9). This campaign took place in the dry season of the Southern Hemisphere and some flight measurements were influenced by biomass 

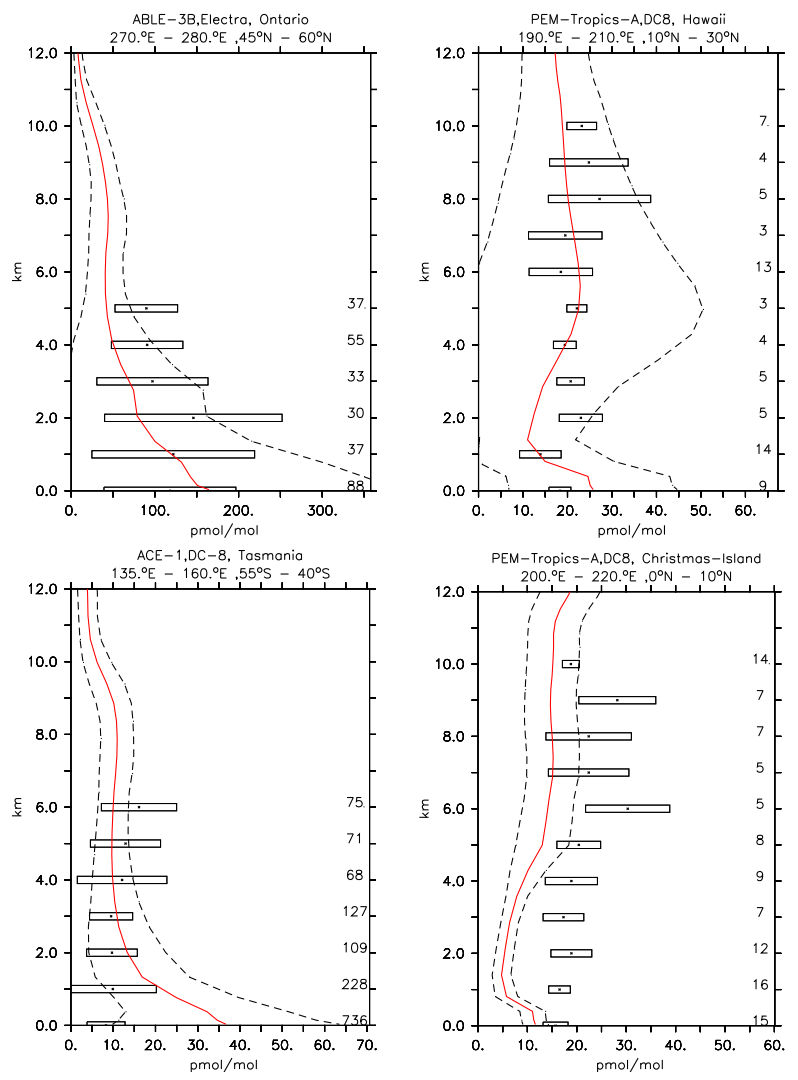

Fig. 11. Vertical profiles of $\mathrm{C}_{3} \mathrm{H}_{8}$ (in $\mathrm{pmol} / \mathrm{mol}$ ) for some selected campaigns. Symbols and colours as in Fig. 8.

burning. Problems occur in the upper troposphere, where the model underestimates the $\mathrm{C}_{2} \mathrm{H}_{6}$ mixing ratio by a factor of 2. Pickering et al. (1996) report that the convection frequency during this campaign was unusually high, which could explain the disagreement between the model and the observations.

For propane, from Tables 1 and 2 we infer that the simulated vertical profiles are in good agreement with the observations (Fig. 11). This agreement is mainly achieved by the realistic representation of the emissions. As pointed out by Wang and Zeng (2004), an increase of $14 \pm 5 \%$ of the emission inventory used by Bey et al. (2001) $(9.66 \mathrm{Tg} / \mathrm{yr})$ was required to correctly match the observations, for an emission total of $11 \mathrm{Tg} / \mathrm{yr}$. In our simulation the total emission was $11.97 \mathrm{Tg} / \mathrm{yr}$ (see Table 5). This amount is still lower than the suggested values present in literature (e.g., $13.46 \mathrm{Tg} / \mathrm{yr}$ calculated by Jacob et al. (2002)).

However, even though the emissions are in the suggested range, the simulated mixing ratios are at the lower end of the measurement range (Fig. 11 and Table 1).
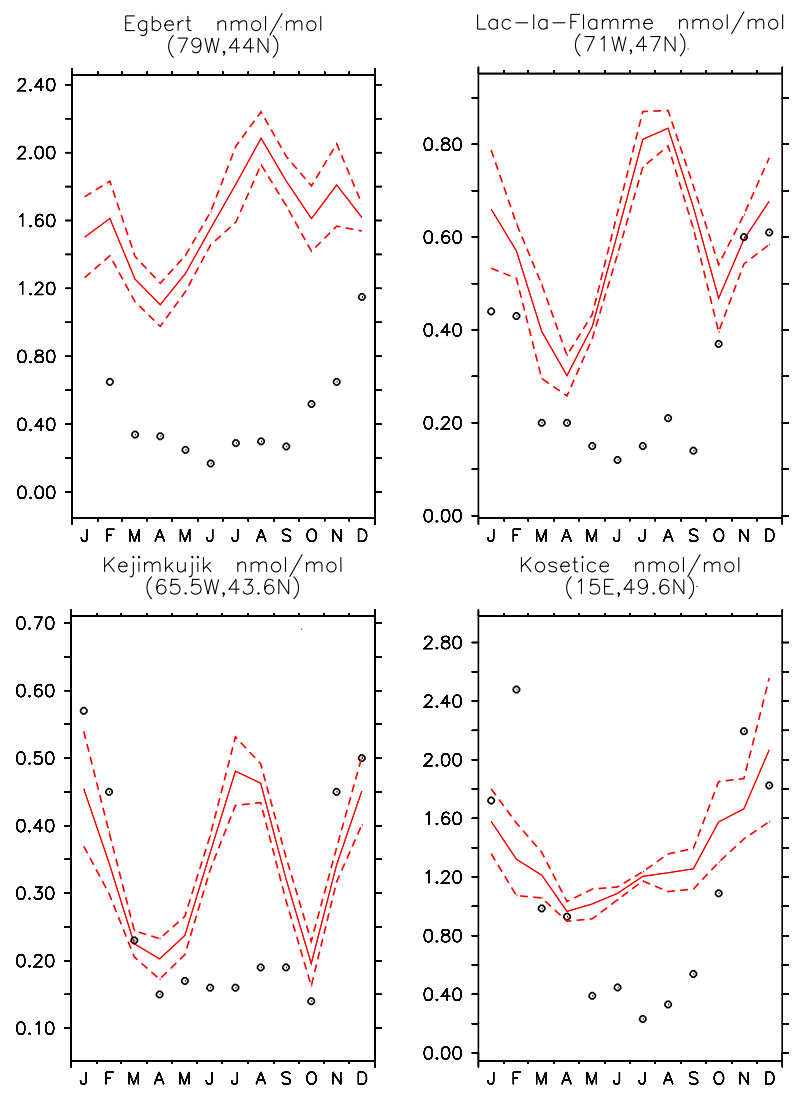

Fig. 12. As Fig. 10, for $\mathrm{C}_{2} \mathrm{H}_{4}$.

\subsection{Alkenes (ethene $\mathrm{C}_{2} \mathrm{H}_{4}$ and propene $\mathrm{C}_{3} \mathrm{H}_{6}$ )}

The alkenes, in contrast to the alkanes, are generally poorly reproduced by the model. The simulated mixing ratios are usually lower than the measurements (Table 1).

Ethene $\left(\mathrm{C}_{2} \mathrm{H}_{4}\right)$ has a poor correlation, both, with surface and aircraft measurements (Tables 2 and 4). This low correlation is due to an overestimation of the mixing ratio at the surface (Fig. 12), where the seasonal cycle is not reproduced with a peak in the mixing ratio during summer. The vertical profiles (Fig. 13) are mostly high biased (e.g., TOPSE-Mar, Boulder), with the largest differences between model results and observations occurring at the surface. In remote regions, where the direct influence of emissions is lower, the model is, nevertheless, at the lower end of the range of observations, with frequent underestimates (TRACE-A, Brazil Coast and South Atlantic).

The emissions from oceans appear too high (see Fig. 13, PEM-Tropics-B, Fiji) and a reduction in the model likely improves the simulation of ethene.

Propene is also not very well simulated by the model. The low correlation (Table 1) indicates a wrong representation of the vertical profiles. This poor representation cannot be reconciled with the variability of the model or measurement 

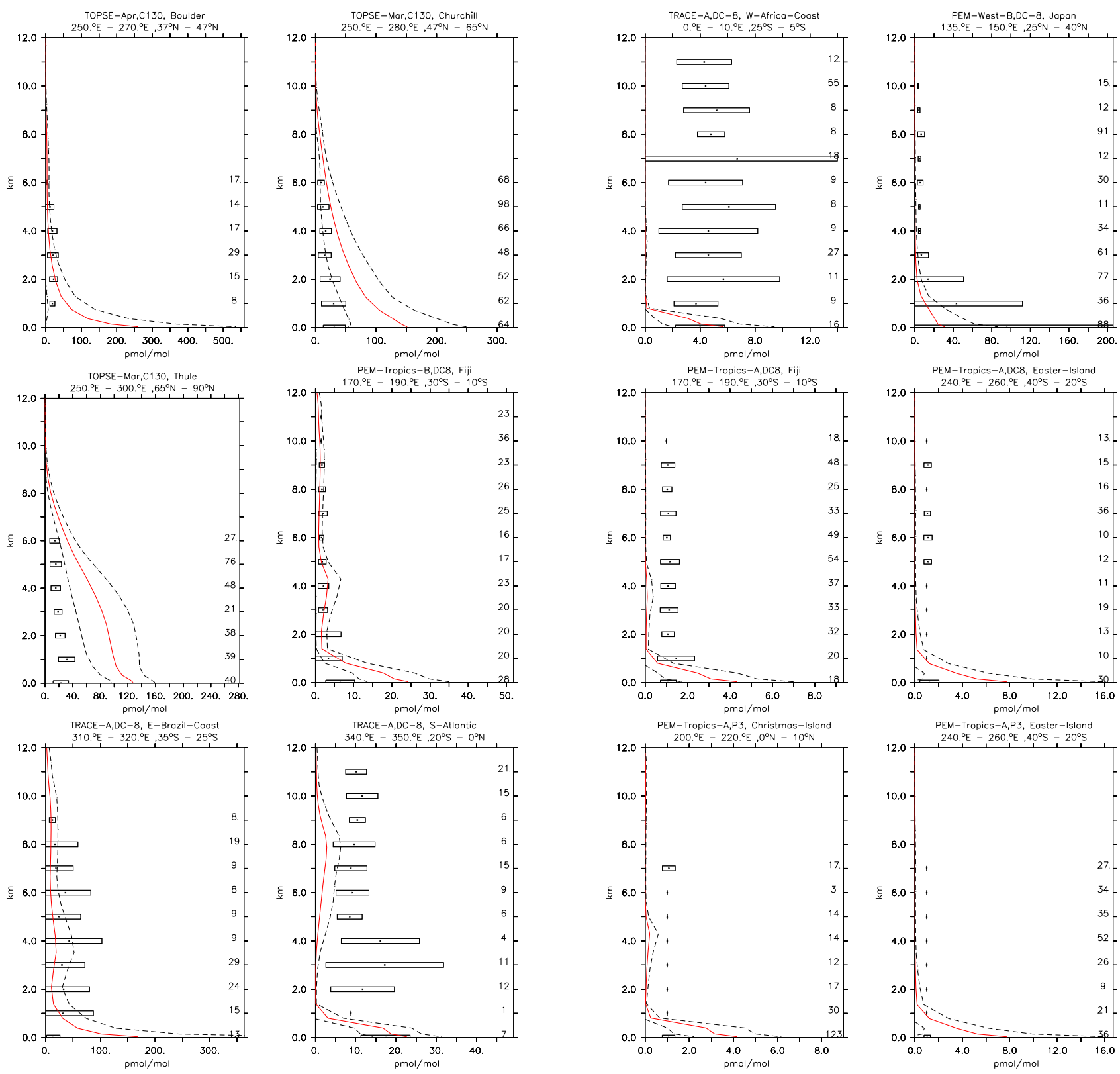

Fig. 13. Vertical profiles of $\mathrm{C}_{2} \mathrm{H}_{4}$ (in pmol/mol) for some selected campaigns. Symbols and colours as in Fig. 8.

uncertainties, since the bias in Table 2 is much larger than one standard deviation. From Fig. 14, the erroneous description of this trace gas in the model is evident. The very high mixing ratio in the boundary layer (2-3 times the observed one) in open ocean regions (PEM-TROPICS-A, all locations) indicates a too strong emission of this tracer from the ocean. In E5/M1 the upper limit of the suggested emission from Bates et al. (1995) has been applied (1.27 Tg/yr).

This overestimation is not so evident in continental regions more strongly influenced by anthropogenic (Fig. 14, PEM-WEST-B, Japan or Fig. 15, Izaña, Lac la Flamme) or

Fig. 14. Vertical profiles of $\mathrm{C}_{3} \mathrm{H}_{6}$ (in pmol/mol) for some selected campaigns. Symbols and colours as in Fig. 8.

biomass burning sources (Fig. 14, TRACE-A, West Africa Coast). Figure 14 shows that outside the planetary boundary layer (PBL), above $2-3 \mathrm{~km}$, the simulated tracer is nearly depleted, in contrast to the observations.

This points to a wrong simulation of the sinks (too fast) which could explain the low values simulated outside the PBL. This tracer is not subject to either wet (due to its low solubility) nor dry deposition and is only removed by reactions with $\mathrm{OH}, \mathrm{NO}_{3}$, and $\mathrm{O}_{3}$, the latter two at least two orders of magnitude slower than the first. The rate coefficient used for the reaction $\mathrm{C}_{3} \mathrm{H}_{6}+\mathrm{OH}$ is taken from the IUPAC 

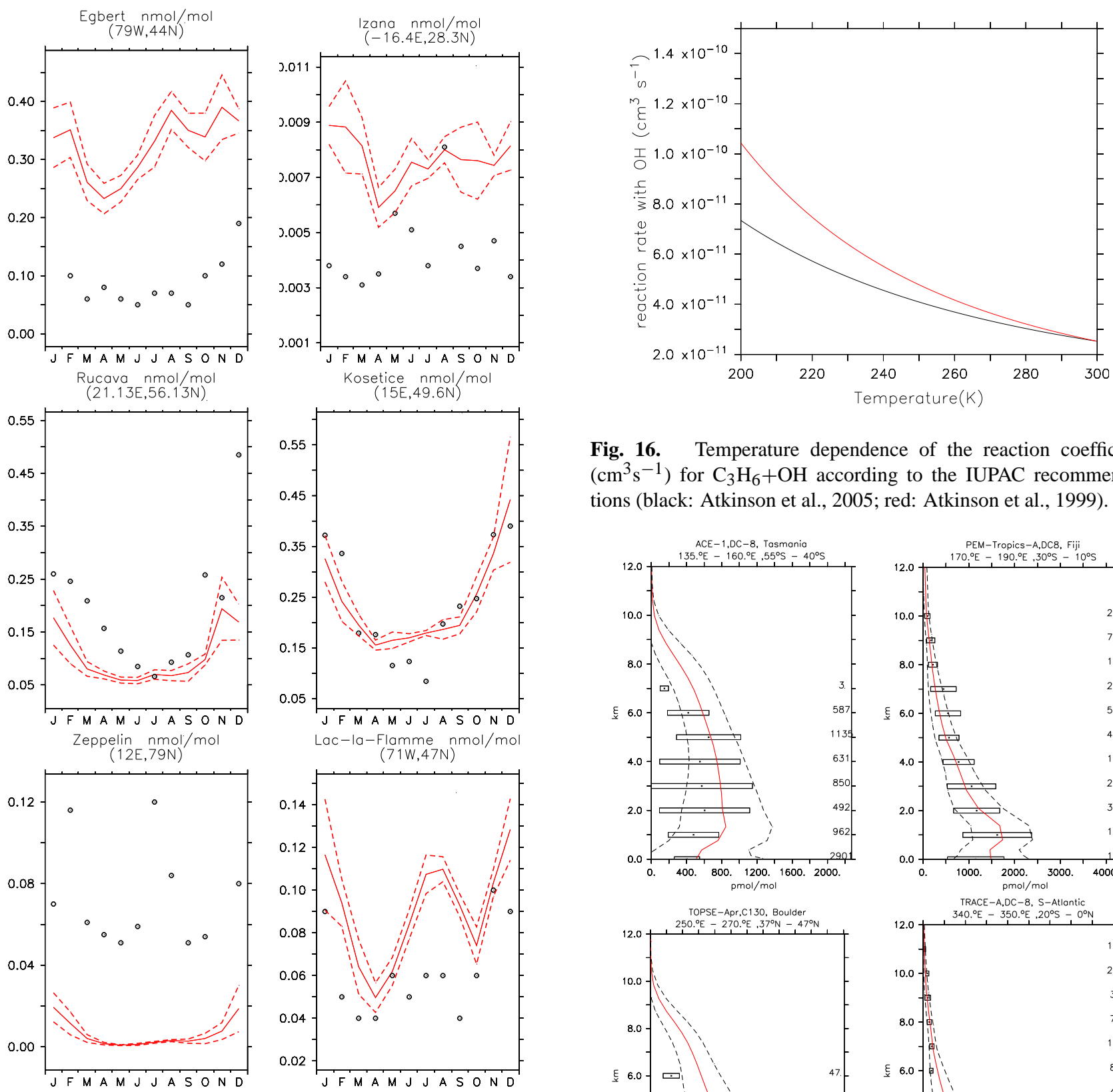

Fig. 15. As Fig. 10, for $\mathrm{C}_{3} \mathrm{H}_{6}$.

Fig. 16. Temperature dependence of the reaction coefficient $\left(\mathrm{cm}^{3} \mathrm{~s}^{-1}\right)$ for $\mathrm{C}_{3} \mathrm{H}_{6}+\mathrm{OH}$ according to the IUPAC recommendations (black: Atkinson et al., 2005; red: Atkinson et al., 1999).
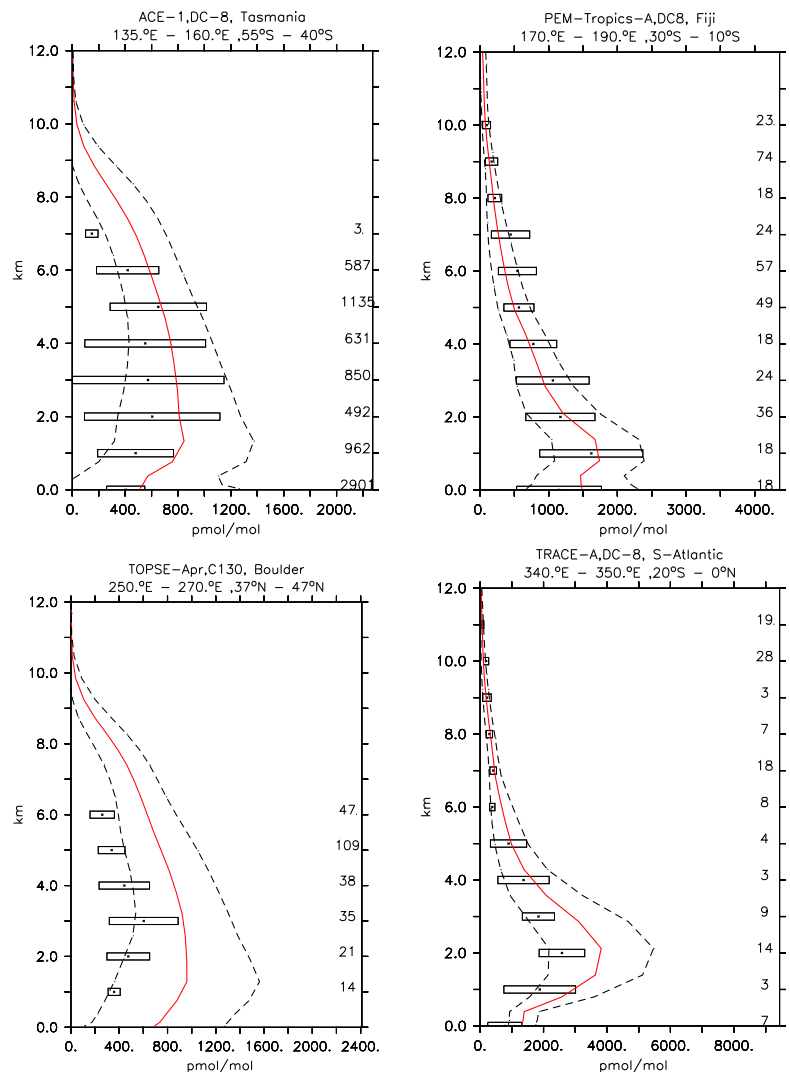

recommendation of 1999 (Atkinson et al., 1999, and references therein). A new recommendation suggests a slightly different dependence of the high pressure channel on temperature (Atkinson et al., 2005; Vakhtin et al., 2003, and references therein). As shown in Fig. 16, the new reaction coefficient is lower than the previously estimated. Although the difference between the two estimates at high temperature is not extreme, our results indirectly support the revision of the reaction coefficient. This will be discussed further in Sect. 8 .

Fig. 17. Vertical profiles of $\mathrm{H}_{2} \mathrm{O}_{2}$ (in pmol/mol) for some selected campaigns. Symbols and colours as in Fig. 8.

\section{Isoprene}

In a test simulation of the first year, the resulting isoprene emission was $580 \mathrm{TgC} / \mathrm{yr}$. This is about $80 \mathrm{TgC}$ larger compared to the offline calculated inventory by Guenther et al. 
(1995), which formed the basis for the implementation of the online calculations of biogenic NMHC emissions in E5/M1 (Ganzeveld et al., 2006; Kerkweg et al., 2006b).

As shown by Houweling et al. (1998), the use of the Guenther et al. (1995) isoprene inventory of $500 \mathrm{TgC} / \mathrm{yr}$ results in a significant overestimation of the simulated tropical Planetary Boundary Layer (PBL) mixing ratios. Consequently, a commonly applied approach in atmospheric chemistry studies, which do not focus on isoprene, is to use a smaller global flux. Different values for the isoprene total emissions have been previously used: $220 \mathrm{TgC} / \mathrm{yr}$ (Brasseur et al., 1998), $350 \mathrm{TgC} / \mathrm{yr}$ (von Kuhlmann et al., 2004), $410 \mathrm{TgC} / \mathrm{yr}$ (Horowitz et al., 2003) and $460 \mathrm{TgC} / \mathrm{yr}$ (Lathiére et al., 2006). Since the main focus of the conducted simulation with E5/M1 has been the evaluation of the global ozone burden and mixing ratios, isoprene fluxes have been scaled to achieve a reduced global annual emission flux. Since isoprene emissions are on-line calculated, they exhibit an interannual variability, resulting in a global emission between 305 and $340 \mathrm{TgC} / \mathrm{yr}$ during the 8 years of the simulation.

\section{Oxygenated compounds}

Oxygenated compounds are partly soluble and are influenced by wet deposition (Tost et al., 2006a) (e.g. $\mathrm{CH}_{3} \mathrm{OOH}$ ), as well as oxidation by $\mathrm{OH}$, and some of them by photolysis $\left(\mathrm{HCHO}, \mathrm{CH}_{3} \mathrm{CHO}, \mathrm{CH}_{3} \mathrm{OOH}\right.$ and $\mathrm{CH}_{3} \mathrm{COCH}_{3}$ ). $\mathrm{Re}-$ producing the vertical profiles of these tracers is therefore challenging, and the identification of the cause of discrepancies between model results and observations is difficult.

\subsection{Hydrogen peroxide, $\mathrm{H}_{2} \mathrm{O}_{2}$}

Hydrogen peroxide is produced by the self reaction of $\mathrm{HO}_{2}$ and can photolyse to produce $\mathrm{OH}$. Hence it is useful as indicator of $\mathrm{HO}_{\mathrm{x}}$ in the troposphere.

As shown in Fig. 17, the vertical profiles of $\mathrm{H}_{2} \mathrm{O}_{2}$ are reasonably well reproduced by the model at different locations and for different field campaigns. Discrepancies from the observations are difficult to define due to its high variability. In fact, from Table 2, the correlation (uncertainty weighted calculation) between model results and measurements is very high $\left(R^{2} \approx 0.94\right)$, mainly because the observed $\mathrm{H}_{2} \mathrm{O}_{2}$ shows a very high variability.

As shown in Fig. 17, $\mathrm{H}_{2} \mathrm{O}_{2}$ is overestimated over Boulder (TOPSE campaign) in the reference simulation. In Fig. 9, at the same location (Boulder, TOPSE campaign), the $\mathrm{C}_{2} \mathrm{H}_{6}$ is underestimated and further analysis revealed the same for CO. This implies an overestimation of the $\mathrm{HO}_{\mathrm{x}}$ radicals in in the simulation $S 1$ and a too strong oxidation capacity of the atmosphere in this region.
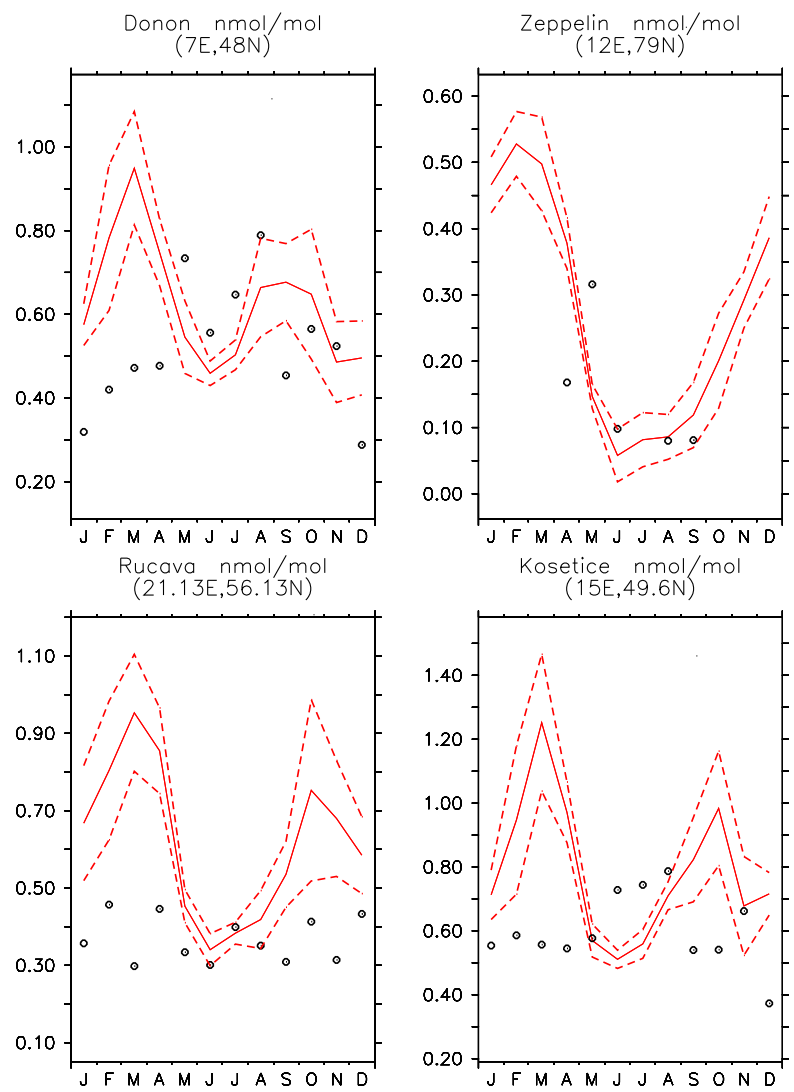

Fig. 18. As Fig. 10, for $\mathrm{CH}_{3} \mathrm{CHO}$.

\subsection{Acetaldehyde, $\mathrm{CH}_{3} \mathrm{CHO}$}

This oxygenated compound is produced from the oxidation of a variety of hydrocarbons (Lewis et al., 2005) and it can produce $\mathrm{HO}_{\mathrm{x}}$ and PAN precursors.

The analysis shows that the model results agree within a factor of two (overestimation) with the observations, although the seasonal cycle is not well reproduced (Fig. 18). This is confirmed by Table 4, which shows that at the surface the amplitude of the seasonal cycle is correct (if we consider the uncertainties), but with the wrong phase $\left(R^{2} \approx 0.298\right)$.

Only a few aircraft measurements are available of this trace gas. Williams et al. (2001) reported a mixing ratio in Suriname in the boundary layer of about $1.7 \mathrm{nmol} / \mathrm{mol}$ and $0.8 \mathrm{nmol} / \mathrm{mol}$ in the free troposphere. The model underestimates these mixing ratios by a factor of 10 . During the PEM-TROPICS-B campaign (Singh et al., 2001) over the open ocean mixing ratios between 60 and $100 \mathrm{pmol} / \mathrm{mol}$ have been measured, about 4 times higher than simulated. Singh et al. (2001) postulate some sources from the ocean (Zhou and Mopper, 1997), though more measurements are required to better constrain the abundance of this tracer. 

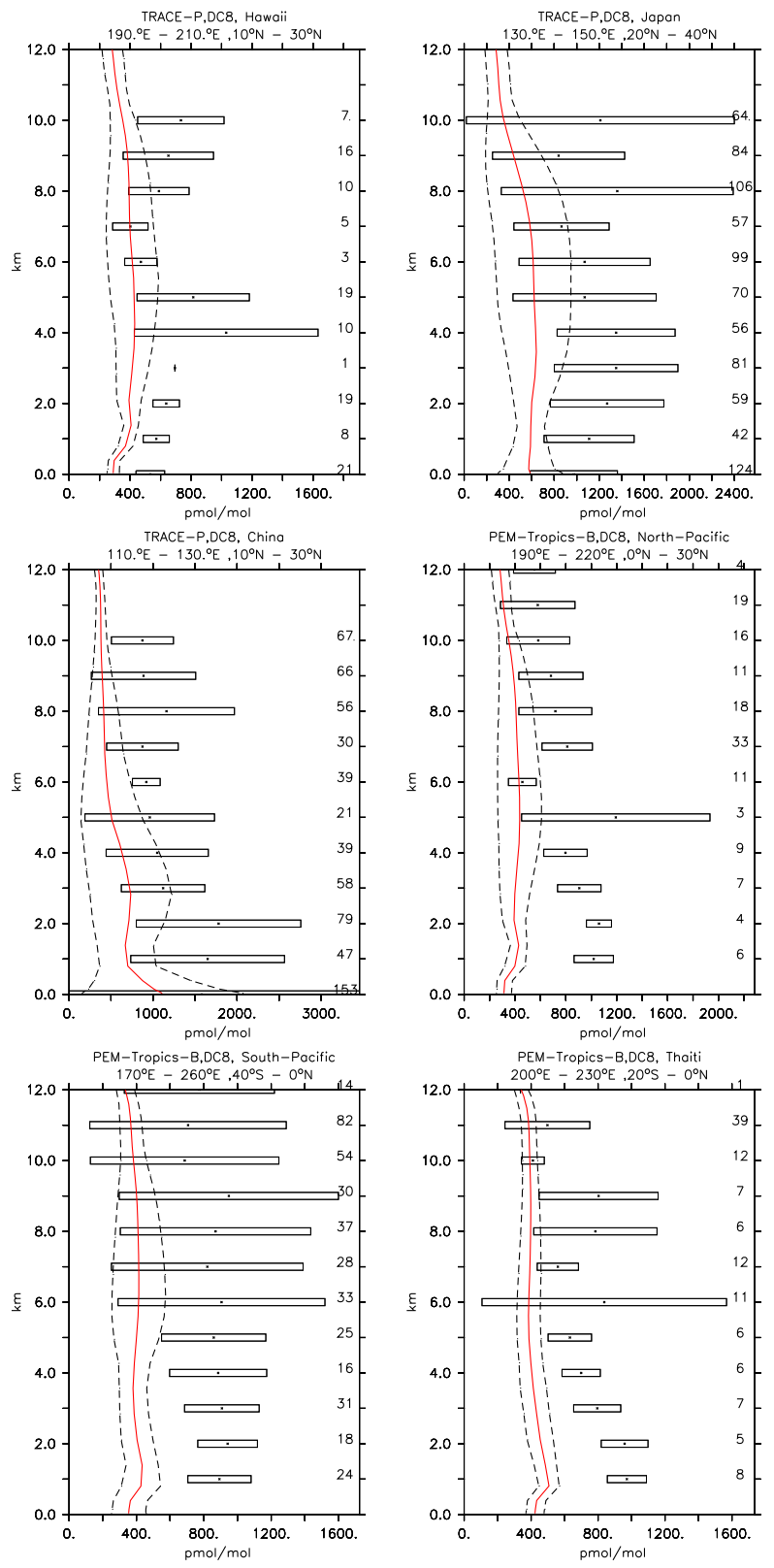

Fig. 19. Vertical profiles of $\mathrm{CH}_{3} \mathrm{OH}$ (in pmol/mol) for some selected campaigns. Symbols and colours as in Fig. 8.

\subsection{Methanol, $\mathrm{CH}_{3} \mathrm{OH}$}

Even though methanol is one of the most abundant organic trace gases in the atmosphere, its global cycle is not well understood (Heikes et al., 2002; Singh et al., 2000; Jacob et al., 2005). It influences the upper tropospheric photochemistry because of its oxidation to formaldehyde (Palmer et al., 2003; Singh et al., 2003; Jacob et al., 2005). Unfortunately, the distribution and magnitude of the sources and sinks are largely unknown (Tie et al., 2003; Singh et al., 2004; Galbally and Kirstine, 2002). Due to these high uncertainties, emissions from the ocean have not been included in our simulation, though indicated by previous studies (Jacob et al., 2005; Heikes et al., 2002).

Compared to other tracers, relatively few observations of methanol are available (PEM TROPICS-B and TRACE-P campaigns). As noted in Sect. 3, the correlation between model results and measurements is very low $\left(R^{2}=0.313\right)$, and the vertical profiles are not reproduced by the model (Figs. 2 and 19). Wet deposition has not been taken into account for this tracer (Tost et al., 2006a), however, only small differences of $\approx 5 \%$ are expected by accounting for this process (Heikes et al., 2002; Galbally and Kirstine, 2002; von Kuhlmann et al., 2003b). The simulated total dry deposition of $42.16 \mathrm{Tg} / \mathrm{yr}$ is well within the suggested values in the literature (e.g. 35-210 Tg/yr (Heikes et al., 2002), 11$43 \mathrm{Tg} / \mathrm{yr}$ (Galbally and Kirstine, 2002), 32-85 Tg/yr (Tie et al., 2003), $37 \mathrm{Tg} / \mathrm{yr}$ (von Kuhlmann et al., 2003b) and $55 \mathrm{Tg} / \mathrm{yr}$ (Jacob et al., 2005)). Thus, underestimated emission fluxes or incomplete description of the chemistry are more likely responsible for the wrong representation. A total emission of $77 \mathrm{Tg} / \mathrm{yr}$ for $\mathrm{CH}_{3} \mathrm{OH}$ has been used, as suggested by EDGAR (with $60 \mathrm{Tg} / \mathrm{yr}$ of biogenic emissions). Note, however, that a recent study by Jacob et al. (2005) recommends a total emission of $168 \mathrm{Tg} / \mathrm{yr}$ with $151 \mathrm{Tg} / \mathrm{yr}$ of biogenic emissions.

\subsection{Formaldehyde, $\mathrm{HCHO}$}

Although formaldehyde is chemically formed by methanol, the low production rate from $\mathrm{CH}_{3} \mathrm{OH}+\mathrm{OH} \rightarrow \mathrm{HCHO}+\mathrm{HO}_{2}$ $\left(k \approx 5 \times 10^{-13} \mathrm{~cm}^{3} \mathrm{molec}^{-1} \mathrm{~s}^{-1}\right)$ indicates that this reaction is not essential for a realistic simulation of formaldehyde and that the wrong representation of methanol is not strongly influencing HCHO (Stickler et al., 2006). The model, in fact, predicts the observed mixing ratios of this trace gas very well (Fig. 20 and Sect. 3).

The simulation is in good agreement with station measurements, and the amplitude of the seasonal cycle is well reproduced at the surface (Figs. 3 and 4), although with a smaller amplitude than observed. From the comparison with the aircraft measurements (Fig. 20 and Sect. 3) we conclude that the simulation of HCHO satisfactorily reproduces the observations. Particularly good agreement is obtained for the PEMTROPICS-B field campaign, where more than 20 measurements per location are available. A systematic underestimation of the measurements is observed at the surface for the TOPSE-A campaign, only for the location Thule (Fig. 20). This can potentially be explained by the absence of emissions of HCHO from snow (Riedel et al., 2005, and references therein). Other models (Fried et al., 2003) also simulate large disagreements compared to measurements for the TOPSE-A campaign. 

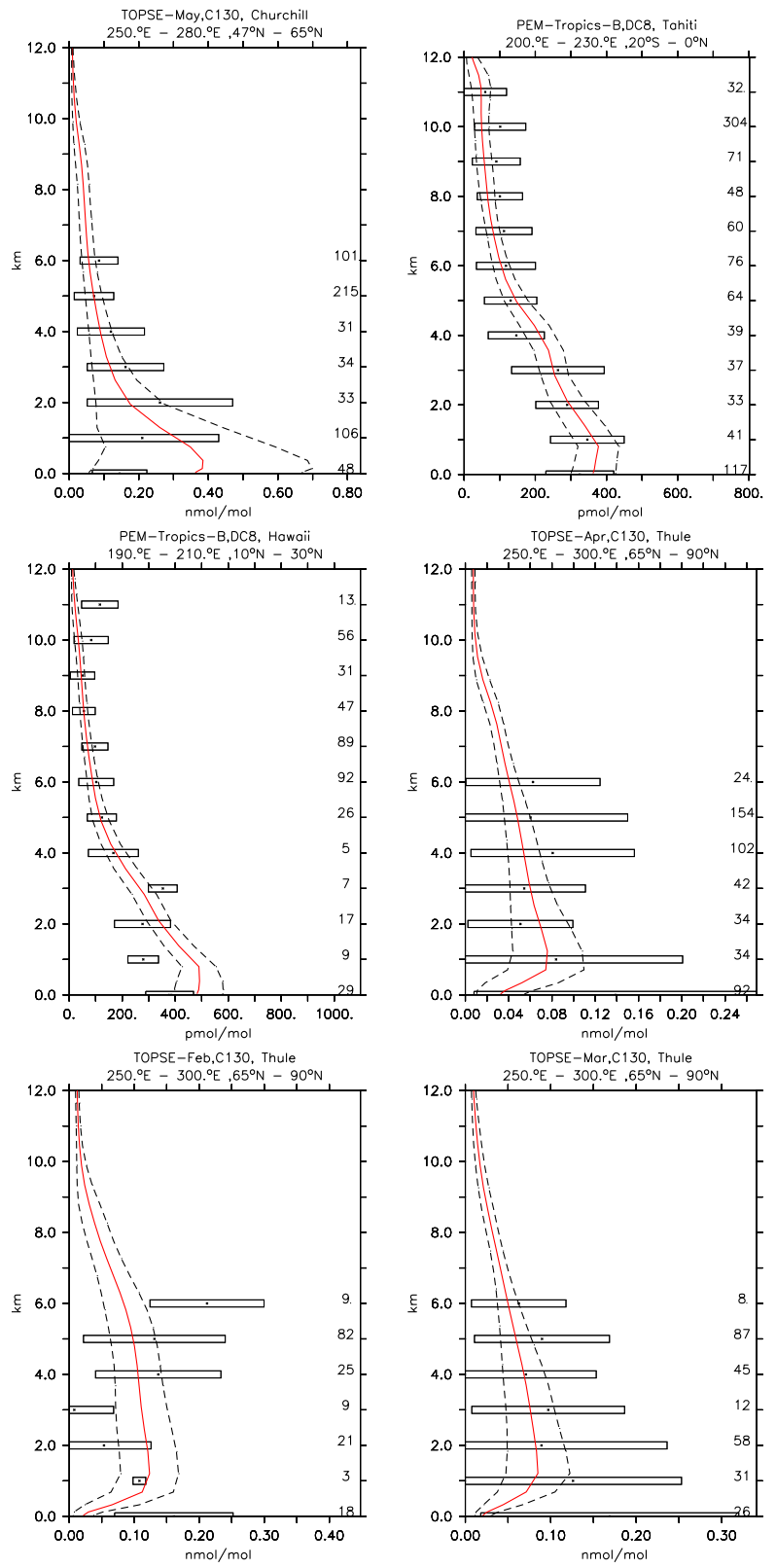

Fig. 20. Vertical profiles of $\mathrm{HCHO}$ for some selected campaigns (unit in the labels). Symbols and colours as in Fig. 8.

\subsection{Acetone, $\mathrm{CH}_{3} \mathrm{COCH}_{3}$}

Acetone $\left(\mathrm{CH}_{3} \mathrm{COCH}_{3}\right)$ plays a significant role in the upper tropospheric $\mathrm{HO}_{\mathrm{x}}$ budget due to its photolysis (Singh et al., 1995; McKeen et al., 1997; Müller and Brasseur, 1995; Wennberg et al., 1998; Jaeglé et al., 2001). Moreover, this tracer is essential to correctly describe the ozone enhancement in flight corridors (Brühl et al., 2000; Folkins and Chatfield, 2000).

Comparing this simulated tracer with the station observations, we conclude that at the surface this tracer is well simu-
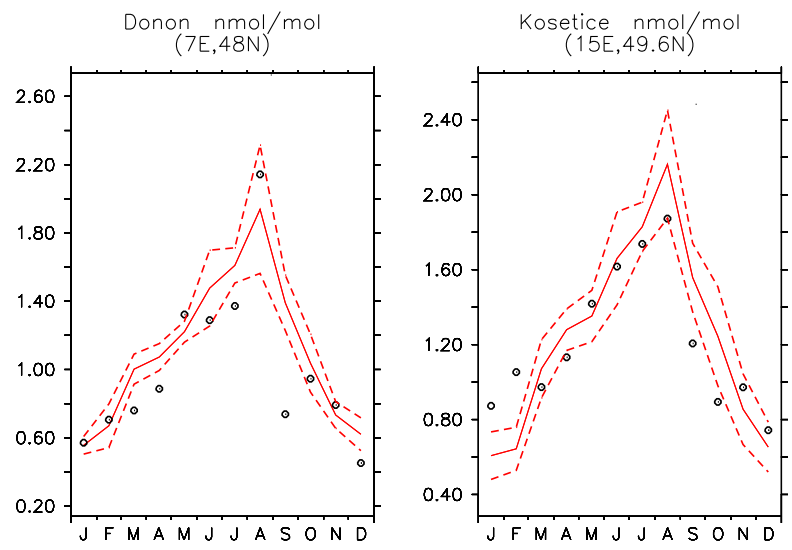

Fig. 21. As Fig. 10, for HCHO.

lated. Problems in reproducing the seasonal cycle are evident for only two locations (see Fig. 22), Zeppelin and Ispra, but Table 3 shows that acetone has one of the highest correlation coefficients and lowest biases compared to other tracers. However, the annual cycle seems to be underestimated (see Figs. 3 and 4). Folberth et al. (2006) suggested biogenic emissions of $55.93 \mathrm{Tg} / \mathrm{yr}$, more than the $42 \mathrm{Tg} / \mathrm{yr}$ used in this simulation.

As also seen for $\mathrm{HCHO}$, this is not the only species with which we have problems at this location, and we cannot rule out that the Ispra site is unrepresentative for the area of one model grid-box.

Although acetone is well reproduced at the surface, large discrepancies with observations are present in the vertical profiles. As shown in Sect. 3, the correlation with the aircraft measurements is low $\left(R^{2}=0.385\right)$, and the vertical profile is not reproduced (bias in Fig. 2). Large discrepancies with observations (Fig. 23) are present in the free troposphere. A comparison of simulated acetone with aircraft measurements is shown in Fig. 24, where the colour code indicates the vertical distribution of the measurements and the corresponding model results.

The differences between model results and observations appears to increase with altitude. The shape of the simulated vertical profiles suggest a potential misrepresentation of the photolysis of this tracer. Measurements made by Blitz et al. (2004) indicate that the quantum yield (and therefore the photolysis rate) of acetone is lower than previously assumed. A reduction would increase the mixing ratio of this tracer and the simulation would then agree better with the observations. Furthermore, as shown by Arnold et al. (2004), this new quantum yield may significantly change the contribution of $\mathrm{CH}_{3} \mathrm{COCH}_{3}$ to the $\mathrm{HO}_{\mathrm{x}}$ budget. Arnold et al. (2005) showed that the new quantum yield decreases the global loss of acetone by a factor of $\approx 2$ and by $80-90 \%$ in the cold upper troposphere. 

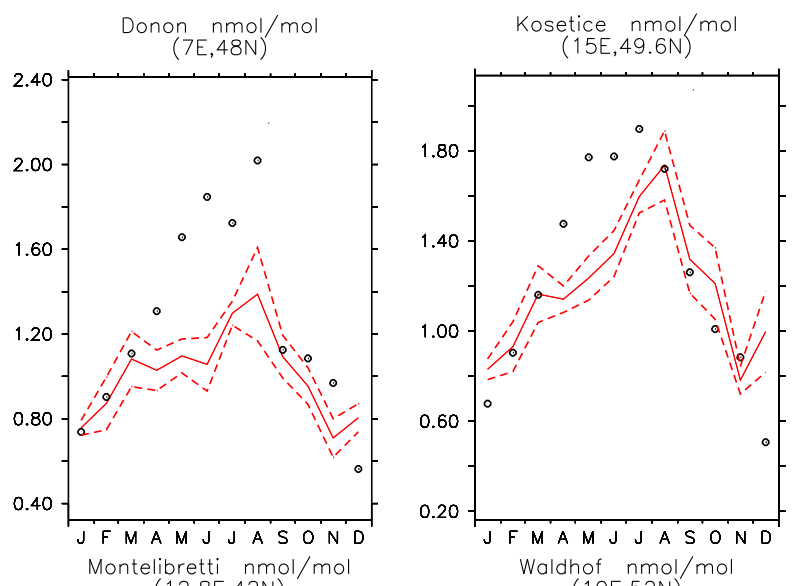

$(12.8 \mathrm{E}, 42 \mathrm{~N})$

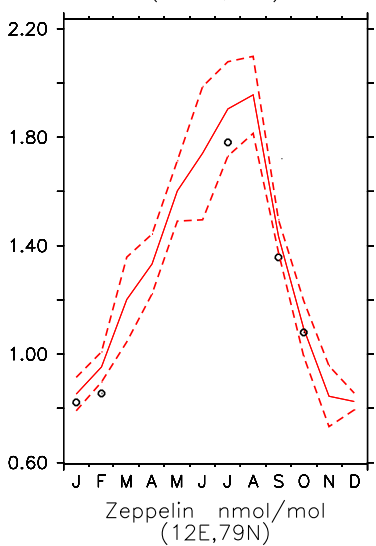

$(10 \mathrm{E}, 52 \mathrm{~N})$
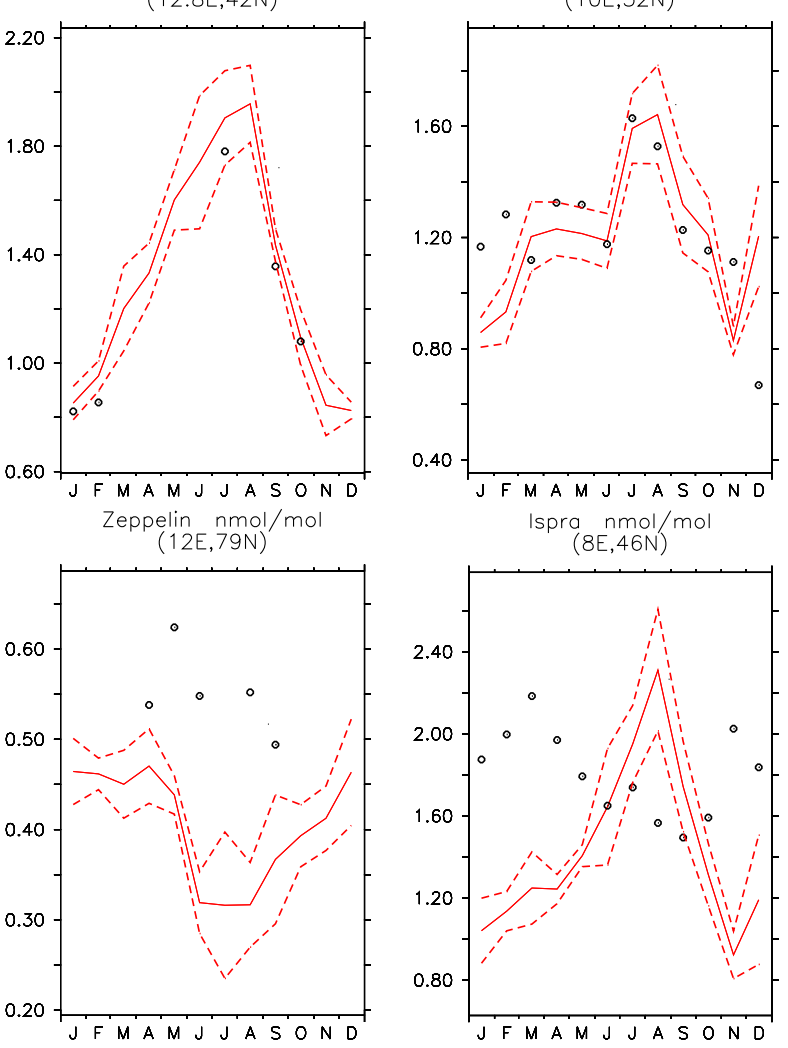

Fig. 22. As Fig. 10, for $\mathrm{CH}_{3} \mathrm{COCH}_{3}$.

The wrong vertical distribution of acetone in our model simulation can also explain the poor correlation of the simulated PAN with the aircraft measurements. As for acetone, the correlation with surface measurements is high, while the simulated vertical profiles strongly deviate from the observed profiles. However, it has to be stressed that the PAN mixing ratios are generally overestimated by the model simulation (Table 2), in contrast to acetone, for which the mixing ratio is systematically underestimated by the model.
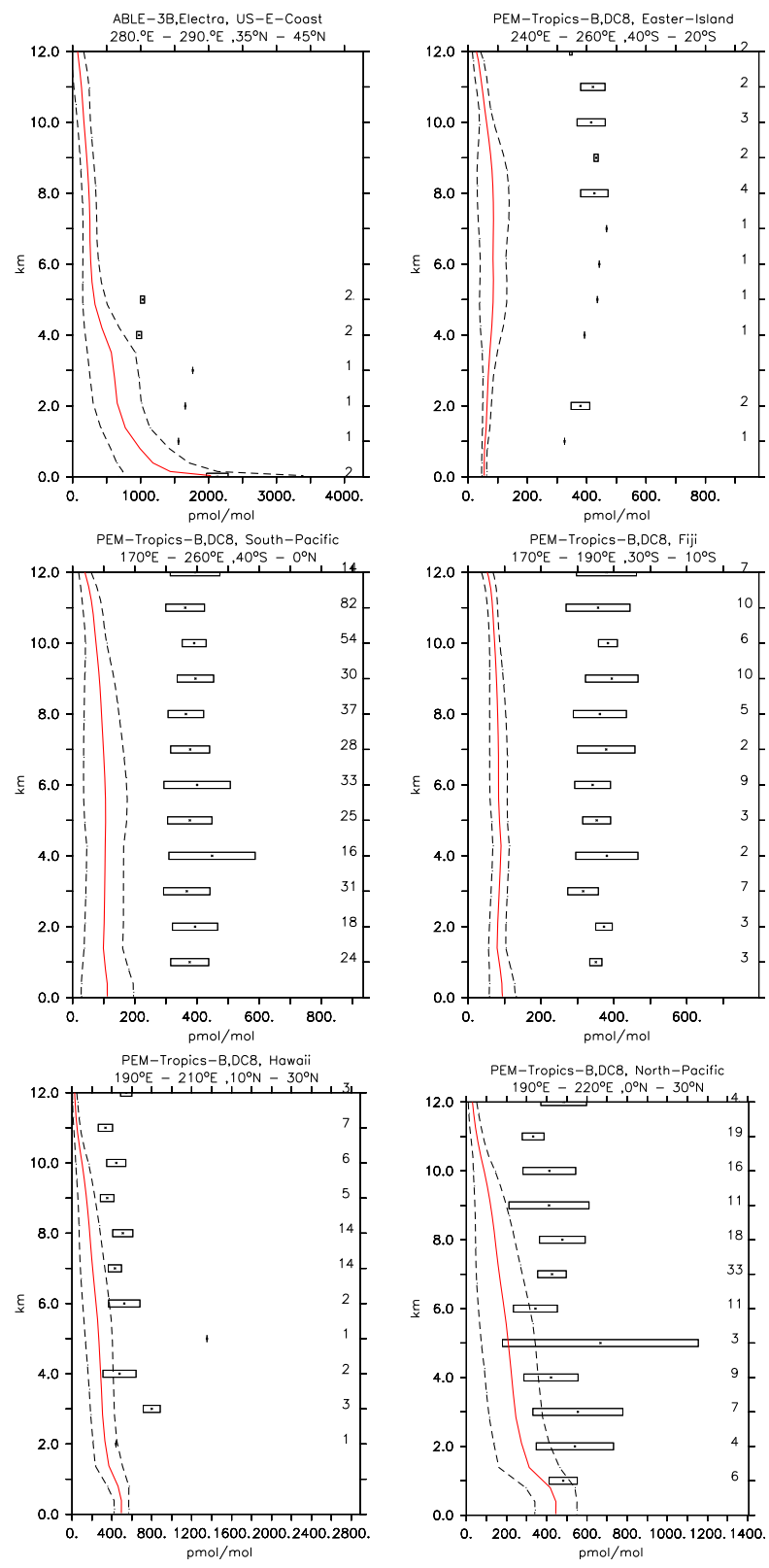

Fig. 23. Vertical profiles of $\mathrm{CH}_{3} \mathrm{COCH}_{3}$ (in pmol/mol) for some selected campaigns. Symbols and colours as in Fig. 8.

\section{Sensitivity studies}

To test the hypotheses posed so far, three additional simulations have been performed for the year 2000. The first simulation (denoted as $S 1 a$ ) is based on the reference simulation S1, presented by Jöckel et al. (2006), with the following modifications:

1. Simulation of dry deposition of $\mathrm{CO}$, based on the few available measurements (Conrad and Seiler, 1985; Sanhueza et al., 1998). We used a constant soil deposition velocity of $0.04 \mathrm{~cm} / \mathrm{s}$ limited to regions where the 


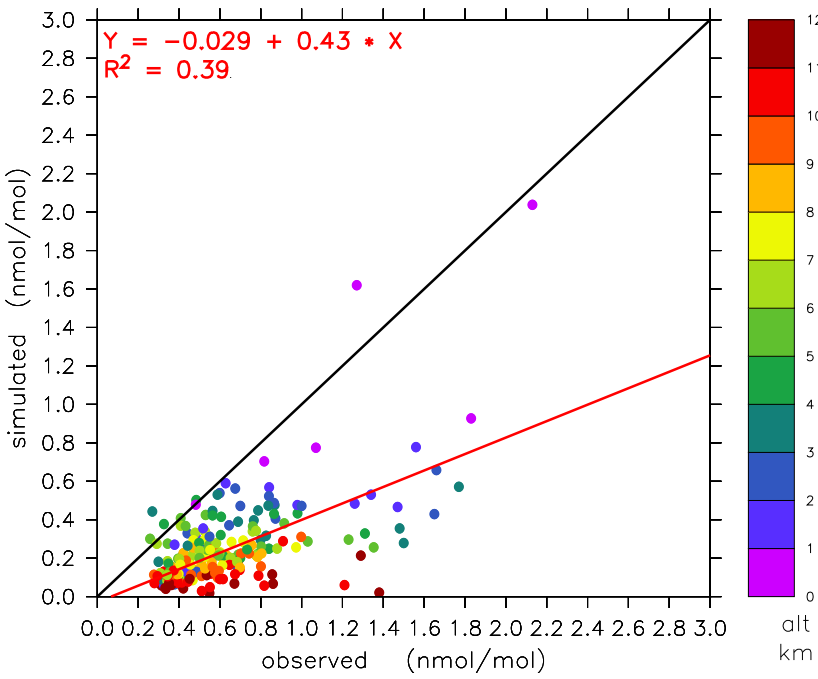

Fig. 24. Scatter plot of simulated versus observed $\mathrm{CH}_{3} \mathrm{COCH}_{3}$. The regression line is shown in red, the one-by-one equivalence is drawn in black.

temperature is higher than $5^{\circ} \mathrm{C}$ and the relative humidity is higher than $40 \%$ in order to exclude cold tundra and desert soils (Lawrence et al., 1999);

2. Increase of the $\mathrm{CO}$ fossil fuel emission over China by $45 \%$ according to Kiley et al. (2003); The new total amount of the CO emission is $1130 \mathrm{Tg} / \mathrm{yr}$, with $314 \mathrm{Tg} / \mathrm{yr}$ due to fossil fuel usage;

3. Changed reaction coefficient for the reaction $\mathrm{C}_{3} \mathrm{H}_{6}+\mathrm{OH}$ as described in Sect. 5.2 (Atkinson et al., 2005);

4. Decrease of the oceanic emission of $\mathrm{C}_{2} \mathrm{H}_{4}$ as suggested by Plass-Dülmer et al. (1995);

5. Increase of the $\mathrm{CH}_{3} \mathrm{OH}$ biogenic emissions to $151 \mathrm{Tg} / \mathrm{yr}$ (Jacob et al., 2005);

6. Increase of the biogenic emissions of $\mathrm{CH}_{3} \mathrm{COCH}_{3}$ to $55.93 \mathrm{Tg} / \mathrm{yr}$ following Folberth et al. (2006);

7. New photolysis of $\mathrm{CH}_{3} \mathrm{COCH}_{3}$ as described by Blitz et al. (2004), Arnold et al. (2004) and Arnold et al. (2005).

In two more sensitivity studies, both based on $S 1 a$, we test the importance of dry deposition. In simulation $S 1 b$, dry deposition of $\mathrm{CO}$ (point 1 of $S 1 a$ ) is switched off. In simulation S1c, the simulation S1a has been repeated, with a changed order of emission and deposition processes in the operator splitting approach. In this special case the dry deposition processes were calculated before the tracer emissions.

Table 7 lists the correlation analysis between sensitivity simulation results and measurements. The same results are
Table 7. Correlation coefficients and linear regression of the comparison of the sensitivity simulations with aircraft observations (model $=m \times$ meas $+b)$. Bias and $\mathrm{b}$ coefficient in $\mathrm{pmol} / \mathrm{mol}$. Bias= model-observations

\begin{tabular}{lccccc}
\hline tracer & num. obs. & bias & $\mathrm{m}$ & $\mathrm{b}$ & $R^{2}$ \\
\hline $\mathrm{C}_{2} \mathrm{H}_{4}($ S1a $)$ & 454 & -24.782 & 0.26 & 9.31 & 0.413 \\
$\mathrm{C}_{3} \mathrm{H}_{6}($ S1a $)$ & 332 & -11.562 & 0.14 & 0.18 & 0.427 \\
$\mathrm{CH}_{3} \mathrm{COCH}_{3}($ Sla $)$ & 246 & -211.95 & 0.57 & 52.00 & 0.429 \\
$\mathrm{CH}_{3} \mathrm{OH}($ S1a $)$ & 116 & -239.05 & 0.28 & 380.84 & 0.273 \\
$\mathrm{CO}($ S1a $)$ & 456 & -6526.8 & 0.53 & 36585 & 0.660 \\
$\mathrm{CO}($ S1b $)$ & 456 & -4003.1 & 0.54 & 37864 & 0.651 \\
$\mathrm{CO}($ S1c $)$ & 456 & -6470.1 & 0.53 & 36966 & 0.656 \\
\hline
\end{tabular}

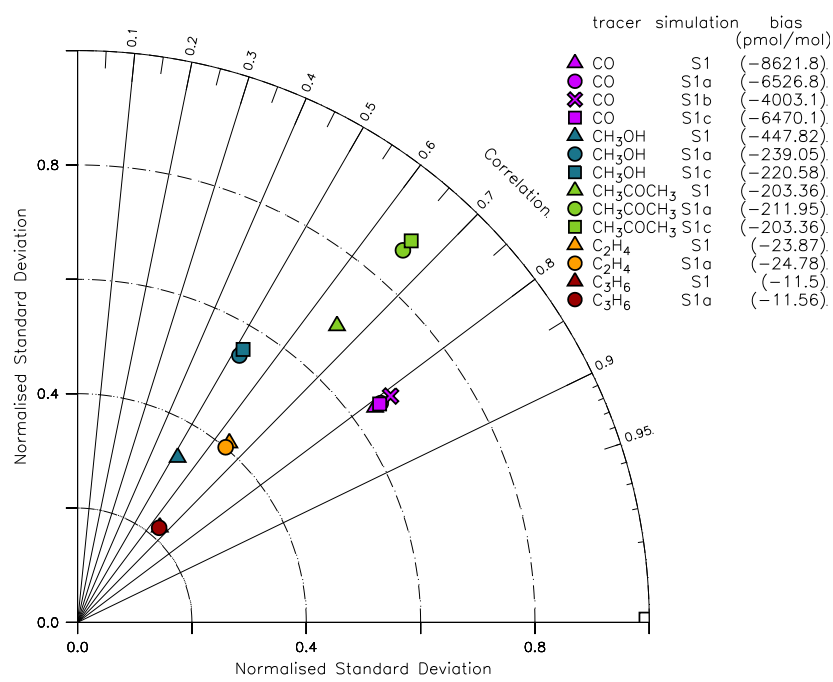

Fig. 25. Taylor diagram of the comparison between aircraft measurements and model results. The color code denotes the tracers and the symbols denote the different sensitivity simulations, respectively. The empty box represents the measurements. The biases are listed in parentheses (in $\mathrm{pmol} / \mathrm{mol}$ ).

depicted in Fig. 25. With the exception of methanol, the model is performing better than in $S 1$, although the improvement is, in general, not substantial.

\subsection{Sensitivity studies $S 1 a$ and $S 1 b$}

The dry deposition of CO, as implemented in Sla, results in a total deposition of $74 \mathrm{Tg} / \mathrm{yr}$, which is within the highly uncertain range of previous estimates: Moxley and Cape (1997) $(540 \pm 430 \mathrm{Tg} / \mathrm{yr})$, Sanhueza et al. (1998) (115-230 Tg/yr), Horowitz et al. (2003) ( $2 \mathrm{Tg} / \mathrm{yr})$, Folberth et al. (2006) $(135 \mathrm{Tg} / \mathrm{yr})$, and Bergamaschi et al. (2000) (301 Tg/yr). The discrepancies between these values cannot be resolved; however, the sensitivity of the model to this process is very low. In Fig. 26, the relative changes between the sensitivity 


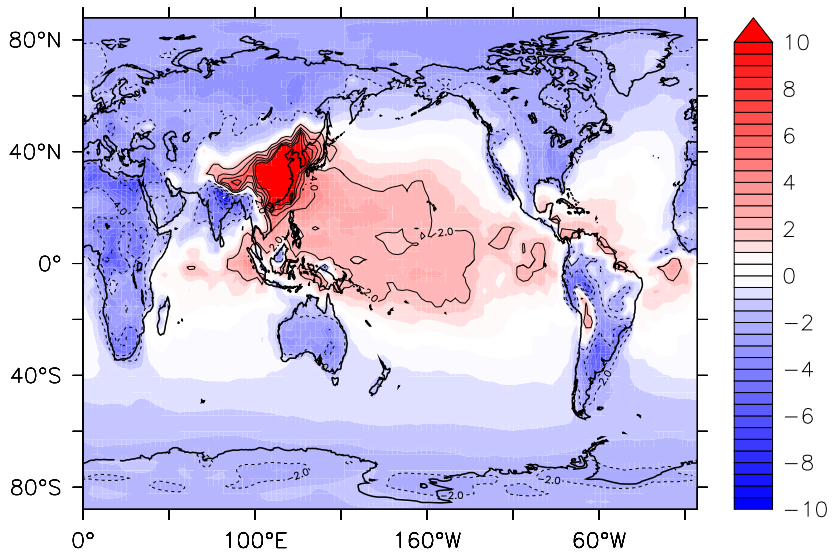

Fig. 26. Relative difference of the annual average $\mathrm{CO}$ mixing ratio at the surface (in \%) between sensitivity simulation Sla (including dry deposition of $\mathrm{CO}$ ) and reference simulation $S 1$ (without dry deposition of $\mathrm{CO}$ ).
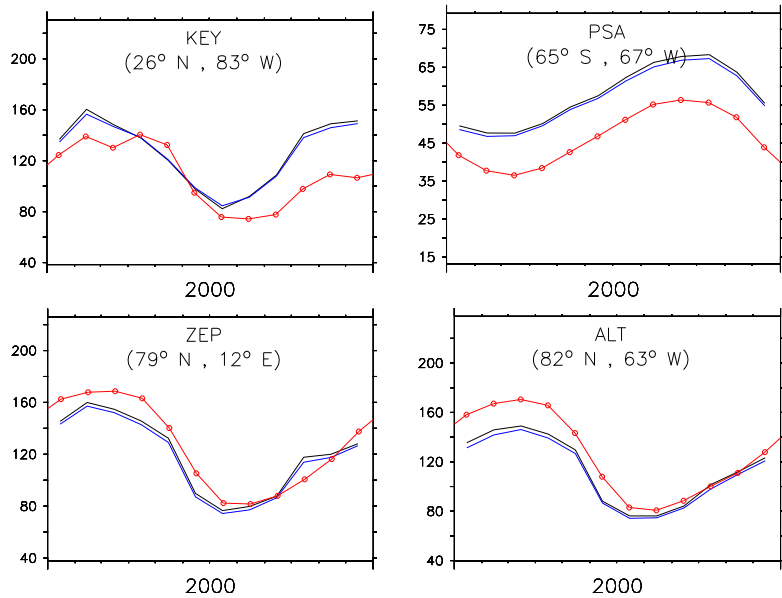

Fig. 27. Comparison of $\mathrm{CO}$ mixing ratios (in $\mathrm{nmol} / \mathrm{mol}$ ): observations are in red, model results are in black (reference simulation S1) and blue (sensitivity simulation S1a). For the locations Florida (KEY) and Palmer station, Antarctica (PSA), the model results are sampled one grid-box upwind (see Sect.4).

study $S 1 a$ and the evaluation simulation $(S 1)$ are shown. For the remote regions the decrease in the $\mathrm{CO}$ mixing ratio is very small (a few percent). No significant improvements of the simulation with respect to the measurements are obtained for remote locations and at the North America stations (see Fig. 27). From Fig. 27 we can also see that dry deposition of $\mathrm{CO}$ decreases the ability of the model to reproduce the $\mathrm{CO}$ mixing ratio at high northern latitudes (Zeppelin, (ZEP) and Alert, (ALT)).

In simulation $S 1 a$, the Chinese emissions of $\mathrm{CO}$ (bio-fuel and fossil fuel usage) have been additionally increased from the originally $80.81 \mathrm{Tg} / \mathrm{yr}$ to $116.9 \mathrm{Tg} / \mathrm{yr}$. This is in agreement with the value of $116 \mathrm{Tg} / \mathrm{yr}$ calculated by Streets et al.

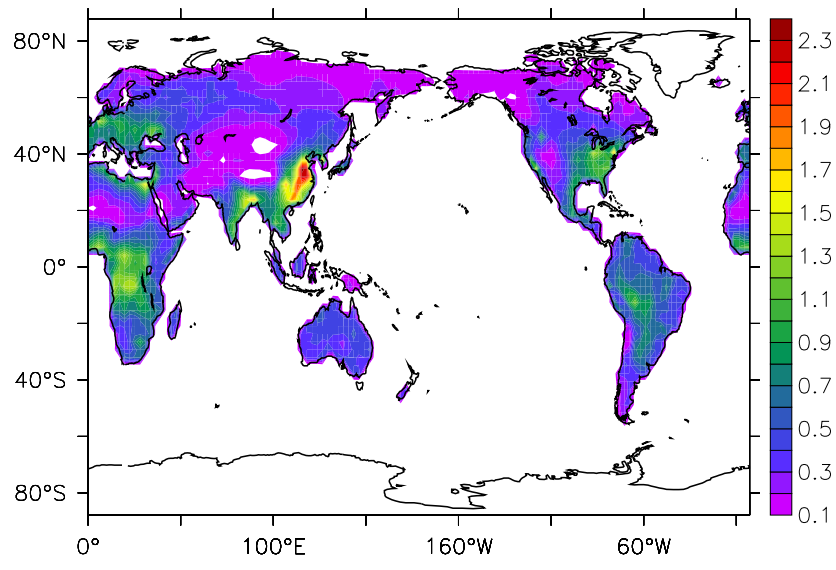

Fig. 28. Annually integrated dry deposition of CO (simulation SIa) in $\mathrm{g} / \mathrm{m}^{2}$.

(2006) based on the TRACE-P campaign for the year 2000. Despite this drastic increase of the $\mathrm{CO}$ emissions over China, the impact on the $\mathrm{CO}$ mixing ratios at the surface, over the ocean downwind is small (Fig. 26).

Although dry deposition is obviously higher where more $\mathrm{CO}$ is emitted (Fig. 28), from Table 7 we deduce that the impact of this process on $\mathrm{CO}$ is marginal. The simulation $S 1 b$, in fact, does not yield significantly different results compared to $S 1 a$. Moreover, as seen in Fig. 29, S1b does not show an improvement of the vertical profiles of CO compared to observations. Nevertheless, there is strong evidence that the Chinese emissions of $\mathrm{CO}$ are underestimated. However, the amount (and the geographic distribution) of the additional unknown sources are not clearly quantifiable (Fig. 29).

Furthermore, as shown in Table 7 and Fig. 27, the dry deposition of $\mathrm{CO}$ only weakly influences the results, and decreases the correlation between the model results and the measurements. We hence conclude that dry deposition of $\mathrm{CO}$, as implemented for simulation Sla, is not suited for future studies.

The changed reaction rate for $\mathrm{C}_{3} \mathrm{H}_{6}$ slightly improves the correlation of this simulated trace gas (see Table 7, $R^{2}=0.427$ ) with aircraft observations. However, the model still simulates a strong depletion in the free troposphere (see Fig. 30), and there is virtually no difference between simulation $S 1$ and simulation Sla near the surface. This is due to the low differences between the two different reaction rates (Atkinson et al., 1999, 2005) at high temperature (i.e. near the surface). The wrong vertical profile implies that the chemical processes related to this tracer are not completely understood; more studies on this tracer (especially on its reaction with $\mathrm{OH}$ ) are required.

The decrease of the oceanic emissions of $\mathrm{C}_{2} \mathrm{H}_{4}$ marginally improves the correlation at a few locations (see Fig. 31) over the ocean and in the marine boundary layer, but overall the resulting differences between $S I$ and $S I a$ are not significant 

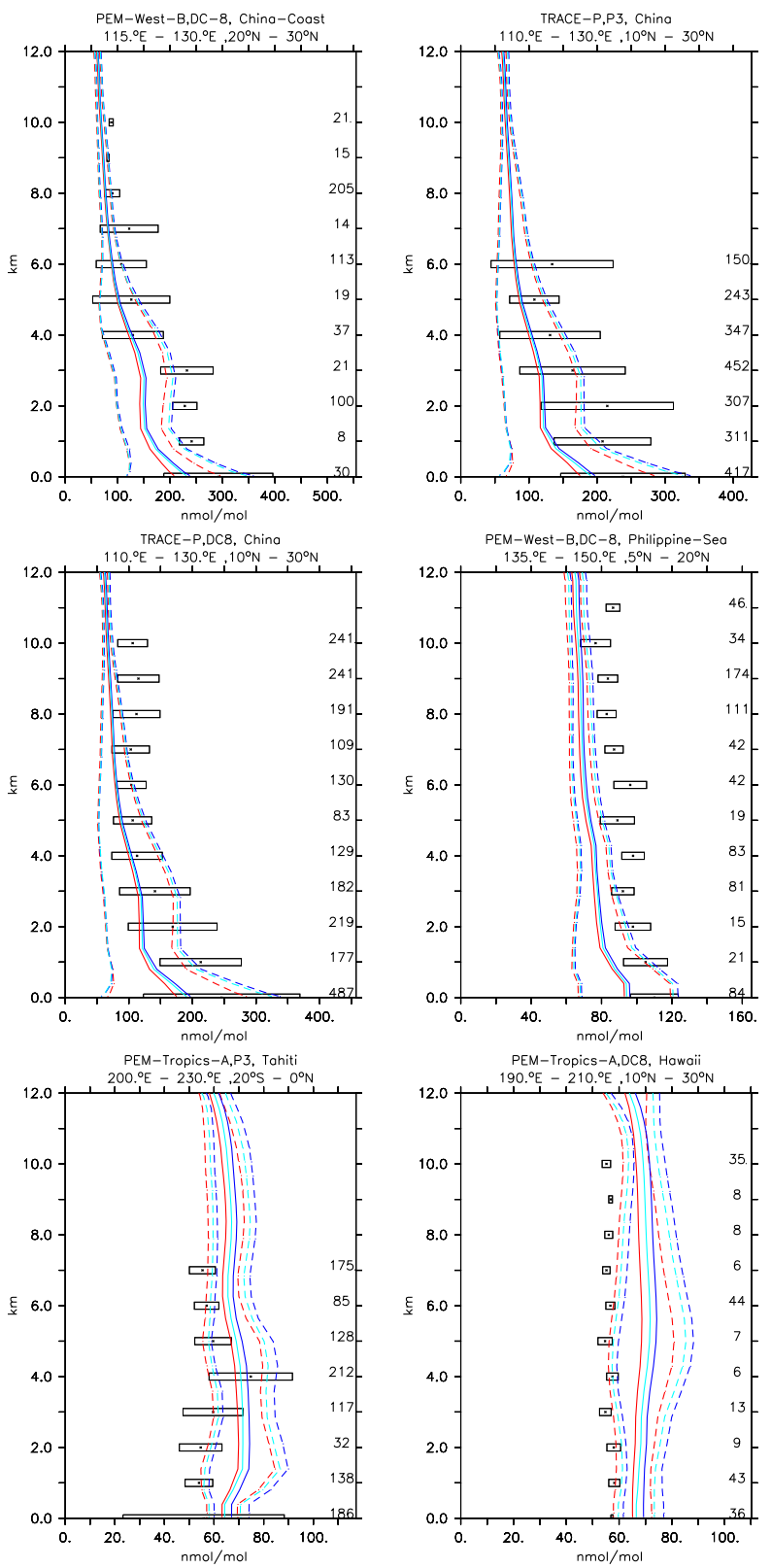

Fig. 29. Vertical profiles of $\mathrm{CO}$ (in $\mathrm{nmol} / \mathrm{mol}$ ) for some selected campaigns from Emmons et al. (2000). Asterisks and boxes represent the average and the standard deviation (w.r.t. space and time) of the measurements in the region, respectively. Red is the reference simulation $S 1$, light blue the simulation $S 1 a$, and dark blue the simulation $S 1 b$. The corresponding standard deviations w.r.t. time and space are indicted by the dashed lines.

$\left(R^{2}=0.413\right.$ for $\left.S 1 a\right)$. We conclude that the major problem is the high uncertainty of the terrestrial $\mathrm{C}_{2} \mathrm{H}_{4}$ sources.

For methanol, Table 7 shows a decrease in the correlation between model results and observations for Sla compared to S1. This is due to an increased scatter of the model results for Sla compared to S1 (Fig. 32). Nevertheless, the over-
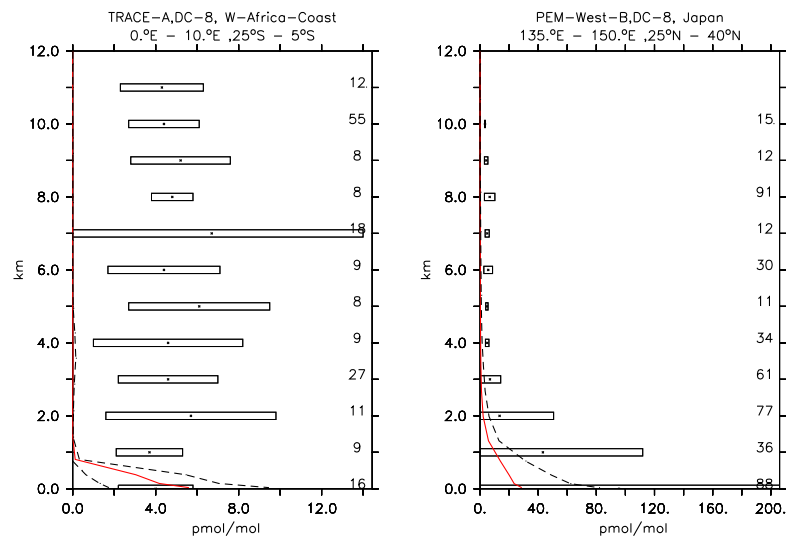

Fig. 30. Vertical profiles of $\mathrm{C}_{3} \mathrm{H}_{6}$ (in pmol/mol) for some selected campaigns and for the sensitivity simulation S1a. Symbols and colours as in Fig. 8.
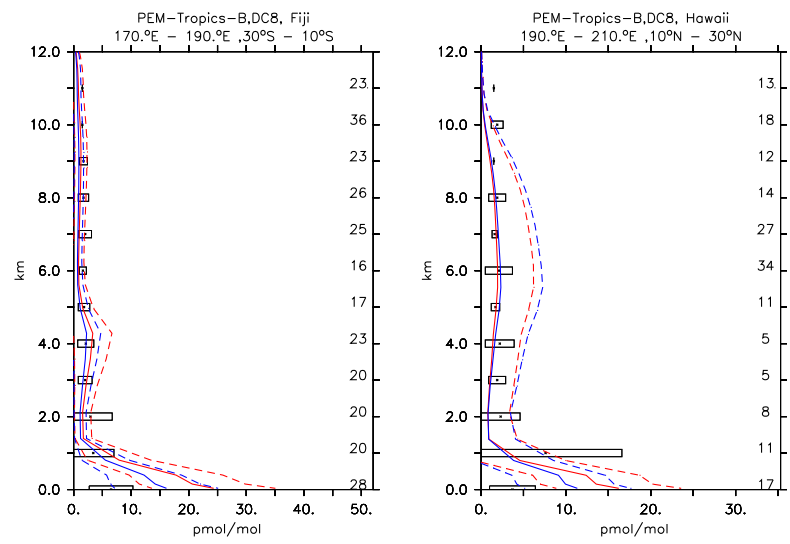

Fig. 31. Vertical profiles of $\mathrm{C}_{2} \mathrm{H}_{4}$ (in pmol/mol) for some selected campaigns. The red line shows the results of the reference simulation $(S 1)$, the blue line the results of the sensitivity simulation S1a. Symbols as in Fig. 8.

all bias is lower in $S 1 a(\approx 239 \mathrm{pmol} / \mathrm{mol})$ than in $S 1$. The dry deposition of methanol increased from $24.20 \mathrm{Tg} / \mathrm{yr}$ in the reference simulation $S 1$ to $82.76 \mathrm{Tg} / \mathrm{yr}$ in the sensitivity simulation S1a. In comparison, Jacob et al. (2005) calculated $55 \mathrm{Tg} / \mathrm{yr}$ dry deposition of methanol and Heikes et al. (2002) and Tie et al. (2003) suggested the ranges $35-210 \mathrm{Tg} / \mathrm{yr}$ and $32-85 \mathrm{Tg} / \mathrm{yr}$, respectively. In conclusion, we recommend to apply the increased amount of biogenic methanol emissions (i.e., $151 \mathrm{Tg} / \mathrm{yr}$ ) of the $S 1 a$ simulation for future studies.

Additionally, the modifications of the model setup for acetone, i.e., the altered photolysis rate calculation, between $S I$ and Sla improved the model results w.r.t. the observations. Figure 33, for example, clearly shows for the TRACE-P campaign (Japan) that the results of the Sla simulation are closer to the observations than those of the $S 1$ simulation. This is quantitatively confirmed by the correlation analysis between the different model results and the observations: for 


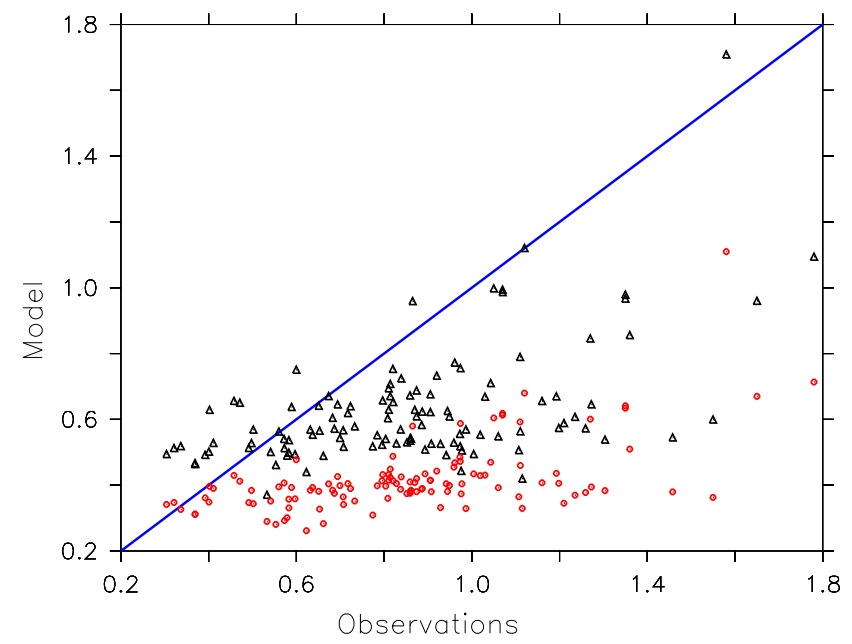

Fig. 32. Scatter plot of model results versus observations of $\mathrm{CH}_{3} \mathrm{OH}$ (both in nmol/mol). The red circles represent the results of the reference simulation $(S 1)$, the black triangles those of the sensitivity simulation $(S 1 a)$.

Table 8. Summary of the correlation coefficients and linear regression analyses of model results versus station observations (model $=$ $m \times$ measurement $+b)$. Bias and $b$ are in $\mathrm{nmol} / \mathrm{mol}$; bias $=$ model results minus observations.

\begin{tabular}{lcccc}
\hline $\mathrm{CH}_{3} \mathrm{COCH}_{3}$ & bias & $\mathrm{m}$ & $\mathrm{b}$ & $R^{2}$ \\
\hline$S 1$ & -0.078 & 0.528 & 0.459 & 0.508 \\
S1a & -0.15 & 0.67 & 0.526 & 0.435 \\
\hline
\end{tabular}

the sensitivity simulation $S 1 a$ the correlation coefficient increased (from $R^{2}=0.385$ to $R^{2}=0.429$ ) and the overall bias decreased (from -376.85 to $-211.95 \mathrm{pmol} / \mathrm{mol}$ ) based on the reference simulation. However, compared with station data, the Sla simulation shows a decrease in the correlation and an increased bias (see Table 8). This implies that the value of $\approx 56 \mathrm{Tg} / \mathrm{yr}$ suggested by Folberth et al. (2006) for the biogenic emissions is too high. Discrepancies between the model results and the observations remain, especially over the oceans and in the upper troposphere (Fig. 33). This is probably related to an oversimplified representation of the deposition/emission of acetone from oceans, an issue under debate (Singh et al., 2001; Jacob et al., 2002; Singh et al., 2003; Marandino et al., 2005).

\subsection{Sensitivity study S1c}

Because we found a remarkably low sensitivity of $\mathrm{CO}$ mixing ratios to the emissions from China (see Sect. 8.1), we want to rule out potential systematic errors connected to the operator splitting as applied in our model. In the standard E5/M1 set up, emission tendencies are calculated before the dry deposition tendencies of trace gases. Therefore, we performed an
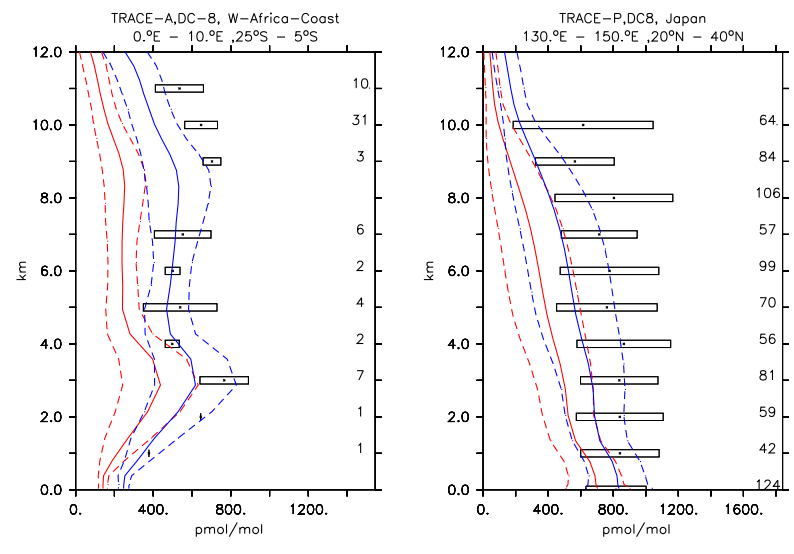

Fig. 33. Vertical profiles of $\mathrm{CH}_{3} \mathrm{COCH}_{3}$ (in pmol/mol) for some selected campaigns. The red line shows the results of the reference simulation $S 1$, the blue line the results of the sensitivity simulation S1a. Symbols as in Fig. 8

Table 9. Annual average dry deposition of different tracers as calculated by the different sensitivity simulations.

\begin{tabular}{lccc}
\hline tracer & $\begin{array}{c}\text { Sla } \\
\mathrm{Tg} / \mathrm{yr}\end{array}$ & $\begin{array}{c}\text { Slc } \\
\mathrm{Tg} / \mathrm{yr}\end{array}$ & $\begin{array}{c}\text { difference } \\
\%\end{array}$ \\
\hline $\mathrm{CO}$ & 74. & 73.6 & -0.5 \\
$\mathrm{CH}_{3} \mathrm{OH}$ & 82.76 & 78.14 & -5.5 \\
$\mathrm{CH}_{3} \mathrm{COCH}$ & 31.25 & 29.82 & -4.57 \\
\hline
\end{tabular}

additional sensitivity simulation $(S 1 c)$ in which we changed the order of processes, such that the dry deposition tendency is calculated before emission tendencies and chemical tendencies. The model setup is the same as for Sla.

As shown in Table 9, the change in the annually averaged dry deposited tracer mass is $5 \%$ at maximum. From this we conclude that the systematic error due to the applied operator splitting is small (as for instance compared to uncertainties in emission estimates) and that the low sensitivity mentioned above is a robust result.

\section{Conclusions}

We presented the second part of the evaluation of the new atmospheric chemistry general circulation model ECHAM5/MESSy1 focusing on organic compounds, including $\mathrm{CO}, \mathrm{C}_{2} \mathrm{H}_{4}, \mathrm{C}_{2} \mathrm{H}_{6}, \mathrm{C}_{3} \mathrm{H}_{6}, \mathrm{C}_{3} \mathrm{H}_{8}, \mathrm{CH}_{3} \mathrm{CHO}, \mathrm{CH}_{3} \mathrm{OH}$, $\mathrm{HCHO}, \mathrm{CH}_{3} \mathrm{COCH}_{3}$, PAN and $\mathrm{H}_{2} \mathrm{O}_{2}$. We compared the model results with observational data obtained from aircraft campaigns and from various sampling stations. We applied regression analyses between the model results and the observations and summarised the results in Taylor diagrams for a quantitative statistical evaluation. 
The seasonal cycle of carbon monoxide is well reproduced by the model, with a very high correlation with observations in remote regions. Some disagreements between the $\mathrm{CO}$ simulation and the NOAA/CMDL surface measurements in polluted areas (which are flagged for "clean air" conditions) can be resolved by sampling the simulated data one grid-box upwind. In this case the correlation between the two datasets increases drastically and the positive bias of the simulation almost disappears.

Our results support the finding of Horowitz et al. (2003) that dry deposition of $\mathrm{CO}$ has been overestimated in many modelling studies so far because the agreement of $\mathrm{CO}$ simulations with observations is best if the dry deposition of $\mathrm{CO}$ is neglected. However, despite the low sensitivity of local $\mathrm{CO}$ to dry deposition, this process might still represent a significant contribution to the global CO budget, as is reflected by the relative high uncertainties presented in the literature.

Although the seasonal cycle of $\mathrm{CO}$ is well reproduced, the model results in the Northern Hemisphere tend to be lower than the observations. This is presumably due to underestimated $\mathrm{CO}$ emissions from fossil fuel combustion in winter.

Overall, the model reproduces most of the observations of alkanes. The simulation of alkenes $\left(\mathrm{C}_{2} \mathrm{H}_{4}\right.$ and $\left.\mathrm{C}_{3} \mathrm{H}_{6}\right)$, however, shows large discrepancies compared to observations, which could not be resolved by the conducted sensitivity studies applying reasonable changes in the model setup. The results strongly indicate that the terrestrial emissions of $\mathrm{C}_{2} \mathrm{H}_{4}$ are significant (though largely unknown) and that the photochemistry of $\mathrm{C}_{3} \mathrm{H}_{6}$ is not yet fully understood.

The quality of the model results for the oxygenated organic compounds is highly dependent on the specific species. While formaldehyde ( $\mathrm{HCHO}$ ) is very well reproduced, the correlations to observations of methanol $\left(\mathrm{CH}_{3} \mathrm{OH}\right)$, acetaldehyde $\left(\mathrm{CH}_{3} \mathrm{CHO}\right)$ and acetone $\left(\mathrm{CH}_{3} \mathrm{COCH}_{3}\right)$ are rather low. The few measurements available for acetaldehyde suggest that the model emissions should be increased by a factor of $\approx 5$, as noticed also by von Kuhlmann et al. (2003b). An increase of the methanol biogenic emissions to $151 \mathrm{Tg} / \mathrm{yr}$ decreases the discrepancies between model results and observations, however, the results are still not satisfactory.

An update of the photolysis rate calculation for acetone according to more recent estimates (Blitz et al., 2004) results in a higher correlation of model results with measurements, and partly solves the problem in the upper troposphere. However, the model calculated mixing ratios remain lower than the observations, especially over the Pacific Ocean. This supports the hypothesis of a missing oceanic source.

Acknowledgements. The authors wish to acknowledge the International Max Planck Research School on Atmospheric Chemistry and Physics for financial support. Special thanks to E. Orlandi for the discussions and the MESSy team for the helpful comments. The authors wish also to acknowledge the use of the Ferret program for analysis and graphics in this paper. Ferret is a product of NOAA's Pacific Marine Environmental Laboratory (information is available at http://www.ferret.noaa.gov).
Edited by: M. Dameris

\section{References}

Arnold, S. R., Chipperfield, M. P., and Blitz, M.: Photodissociation of acetone: Atmospheric implications of temperaturedependent quantum yields, Geophys. Res. Lett., 31, L07110, doi:10.1029/2003GL019099, 2004.

Arnold, S. R., Chipperfield, M. P., and Blitz, M.: A threedimensional model study of the effect of new temperaturedependent quantum yields for acetone photolysis, Geophys. Res. Lett., 110, D22305, doi:10.1029/2005JD005998, 2005.

Atkinson, R.: Atmospheric chemistry of VOCs and $\mathrm{NO}_{\mathrm{x}}$, Atmos. Environ., 34, 2063-2101, 2000.

Atkinson, R., Baulch, D. L., Cox, R. A., Hampson, Jr., R. F., Kerr, J. A., Rossi, M. J., and Troe, J.: Summary of evaluated kinetic and photochemical data for atmospheric chemistry, web version August 1999, http://www.iupac-kinetic.ch.cam.ac.uk/, 1999.

Atkinson, R., Baulch, D. L., Cox, R. A., Crowley, J. N., Hampson Jr., R. F., Hynes, R. G., Jenkin, M. E., Kerr, J. A., Rossi, M. J., and Troe, J.: Summary of evaluated kinetic and photochemical data for atmospheric chemistry, web version March 2005, http: //www.iupac-kinetic.ch.cam.ac.uk/, 2005.

Bates, T. S., Kelly, K. C., Johnson, J. E., and Gammon, R. H.: Regional and seasonal variations in the flux of oceanic carbon monoxide to the atmosphere, J. Geophys. Res., 100, $23093-$ $23101,1995$.

Bergamaschi, P., Hein, R., Heimann, M., and Crutzen, P. J.: Inverse modeling of the global $\mathrm{CO}$ cycle, 1 . Inversion of $\mathrm{CO}$ mixing ratios, J. Geophys. Res., 105, 1909-1927, 2000.

Bey, I., Jacob, D. J., Yantosca, R. M., Logan, J. A., Field, B. D., Fiore, A. M., Li, Q., Liu, H. Y., Mickley, L. J., and Schultz, M. G.: Global modeling of tropospheric chemistry with assimilated meteorology: Model description and evaluation, J. Geophys. Res., 106, 23 073-23 095, 2001.

Blitz, M., Heard, D., Pilling, M., Arnold, S. R., and Chipperfield, M. P.: Pressure and temperature-dependent quantum yields for the photodissocuation od acetone between 279 and $327.5 \mathrm{~nm}$, Geophys. Res. Lett., 31, L06111, doi:10.1029/2003GL018793, 2004.

Brasseur, G. P., Hauglustaine, D. A., Walters, S., Rasch, P. J., and Müller, J.-F.: MOZART, a global chemical transport model for ozone and related chemical tracers, 1. Model description, J. Geophys. Res., 103, 28 265-28 269, 1998.

Brühl, C., Pöschl, U., Crutzen, P. J., and Steil, B.: Acetone and PAN in the upper troposphere: impact on ozone production from aircraft emissions, Atmos. Environ., 34, 3931-3938, 2000.

Conrad, R. and Seiler, W.: Influence of temperature, moisture, and organic carbon on the flux of $\mathrm{H}_{2}$ and $\mathrm{CO}$ between soil and atmosphere: Field studies in subtropical regions, J. Geophys. Res., 90(D3), 5699-5709, 1985.

Emmons, L. K., Hauglustaine, D. A., Müller, J.-F., Carroll, M. A., Brasseur, G. P., Brunner, D., Staehelin, J., Thouret, V., and Marenco, A.: Data composites of airborne observations of tropospheric ozone and its precursors, J. Geophys. Res., 105, $20497-$ 20 538, 2000.

Folberth, G., Hauglustaine, D., Lathiere, J., and Brocheton, F.: Interactive chemistry in the Laboratoire de Meteorologie Dy- 
namique general circulation model: model description and impact analysis of biogenic hydrocarbons on tropospheric chemistry, Atmos. Chem. Phys., 6, 2273-2319, 2006, http://www.atmos-chem-phys.net/6/2273/2006/.

Folkins, I. and Chatfield, R.: Impact of acetone on ozone production and $\mathrm{OH}$ in the upper troposphere at high NOx, J. Geophys. Res., 105, 11 585-11 599, 2000.

Fried, A., Wang, Y., Cantrell, C., Wert, B., Walega, J., Ridley, B., Atlas, E., Shetter, R., Lefer, B., Coffey, M. T., Hannigan, J., Blake, D., Blake, N., Meinardi, S., Talbot, B., Dibb, J., Scheuer, E., Wingenter, O., Snow, J., Heikes, B., and Ehhalt, D.: Tunable diode laser measurements of formaldehyde during the TOPSE 2000 study: Distributions, trends,, J. Geophys. Res., 108(D4), 8365, doi:10.1029/2002JD002208, 2003.

Galbally, I. E. and Kirstine, W.: The production of methanol by flowering plants and the global cycle of methanol, J. Atmos. Chem., 43, 195-229, 2002.

Ganzeveld, L., van Aardenne, J., Butler, T., Jöckel, P., Kerkweg, A., Lawrence, M., Metzger, S., Stier, P. Zimmerman, P., and Lelieveld, J.: Technical Note: Anthropogenic and natural offline emissions and the online EMissions and dry DEPosition (EMDEP) submodel of the Modular Earth Submodel system (MESSy), Atmos. Chem. Phys. Discuss., 6, 5457-5483, 2006, http://www.atmos-chem-phys-discuss.net/6/5457/2006/.

Guenther, A., Hewitt, C. N., Erickson, D., Fall, R., Geron, C., Graedel, T., Harley, P., Klinger, L., Lerdau, M., McKay, W. A., Pierce, T., Scholes, B., Steinbrecher, R., Tallamraju, R., Taylor, J., and Zimmerman, P.: A global model of natural volatile organic compound emissions, J. Geophys. Res., 100, 8873-8892, 1995.

Haas-Laursea, D. and Hartley, D.: Consistent sampling methods for comparing models to $\mathrm{CO}_{2}$ flask data, J. Geophys. Res., 102, 19 059-19071, 1997.

Hauglustaine, D. A., Brasseur, G. P., Walters, S., Rasch, P. J., Müller, J.-F., Emmons, L. K., and Carroll, M. A.: MOZART, a global chemical transport model for ozone and related chemical tracers, 2: Model results and evaluation, J. Geophys. Res., 103, 28 291-28 335, 1998.

Heikes, B. G., Chang, W., Pilson, M. E. Q., Swift, E., Singh, H. B., Guenther, A., Jacob, D. J., Field, B. D., Fall, R., Riemer, D., and Brand, L.: Atmospheric methanol budget and ocean implication, Global Biogeochem. Cycles, 16, 1133, doi:10.1029/2002GB001895, 2002.

Horowitz, L. W., Walters, S., Mauzerall, D. L., Emmons, L. K., Rasch, P. J., Granier, C., Tie, X., Lamarque, J.-F., Schultz, M. G., Tyndall, G. S., Orlando, J. J., and Brasseur, G. P.: A global simulation of tropospheric ozone and related tracers: Description and evaluation of MOZART, version 2, J. Geophys. Res., 108, 4784, doi:10.1029/2002JD002853, 2003.

Houweling, S., Dentener, F., and Lelieveld, J.: The impact of nonmethane hydrocarbon compounds on tropospheric photochemistry, J. Geophys. Res., 103, 10 673-10 696, 1998.

Jacob, D., Field, B., Jin, E., Bey, I., Li, Q., Logan, J., and Yantosca, R.: Atmospheric budget of acetone, J. Geophys. Res., 107, 4100, doi:10.1029/2001JD000694, 2002.

Jacob, D. J., Field, B. D., Li, Q., Blake, D. R., de Gouw, J., Warneke, C., Hansel, A., Wisthaler, A., Singh, H. B., and Guenther, A.: Global budget of methanol: Constraints from atmospheric observations, J. Geophys. Res., 110,
doi:10.1029/2004JD005172, 2005.

Jaeglé, L., Jacob, D. J., Brune, W. H., and Wennberg, P. O.: Chemistry of $\mathrm{HO}_{x}$ radicals in the upper troposphere, Atmos. Environ., 35, 469-489, 2001.

Jeuken, A., Siegmund, P., Heijboer, L., Feichter, J., and Bengtsson, L.: On the potential assimilating meteorological analyses in a global model for the purpose of model validation, J. Geophys. Res., 101, 16939-16 950, 1996.

Jöckel, P., Sander, R., Kerkweg, A., Tost, H., and Lelieveld, J.: Technical Note: The Modular Earth Submodel System (MESSy) - a new approach towards Earth System Modeling, Atmos. Chem. Phys., 5, 433-444, 2005,

http://www.atmos-chem-phys.net/5/433/2005/.

Jöckel, P., Tost, H., Pozzer, A., Brühl, C., Bucholz, J., L., G., Hoor, P., Kerkweg, A., Lawrence, M., Sander, R., Steil, B., Stiller, G., Tanarhte, M., Taraborrelli, D., van Aardenne, J., and Lelieveld, J.: Evaluation of the atmospheric chemistry GCM ECHAM5/MESSy: Consistent simulation of ozone in the stratosphere and troposphere, Atmos. Chem. Phys., 6, 5067-5104, 2006, http://www.atmos-chem-phys.net/6/5067/2006/.

Kerkweg, A., Buchholz, J., Ganzeveld, L., Pozzer, A., Tost, H., and Jöckel, P.: Technical Note: An implementation of the dry removal processes DRY DEPosition and SEDImentation in the Modular Earth Submodel System (MESSy), Atmos. Chem. Phys., 6, 4617-4632, 2006 .

Kerkweg, A., Sander, R., Tost, H., and Jöckel, P.: Technical Note: Implementation of prescribed (OFFLEM), calculated (ONLEM), and pseudo-emissions (TNUDGE) of chemical species in the Modular Earth Submodel System (MESSy), Atmos. Chem. Phys., 6, 3603-3609, 2006b.

Kiley, C. M., Fuelberg, H. E., Palmer, P. I., Allen, D., Carmichael, G., Jacob, D., Mari, C., Pierce, R., Pickering, K., Tang, Y., Wild, O., Fairlie, T., Logan, J., Sachse, G., Shaack, T., and Streets, D.: An intercomparison and evaluation of aircraft-derived and simulated CO from seven chemical transport models during the TRACE-P experiment, J. Geophys. Res., 108(D21), 8819, doi:10.1029/2002JD003089, 2003.

Lathiére, J., Hauglustaine, D., Friend, A., De Noblet-Ducoudré, N., Viovy, N., and Folberth, G.: Impact of climate variability and land use changes on global biogenic volatile organic compound emissions, Atmos. Chem. Phys., 6, 2129-2146, 2006, http://www.atmos-chem-phys.net/6/2129/2006/.

Lawrence, M. G., Crutzen, P. J., Rasch, P. J., Eaton, B. E., and Mahowald, N. M.: A model for studies of tropospheric photochemistry: Description, global distributions, and evaluation, J. Geophys. Res., 104, 26 245-26 277, 1999.

Lelieveld, J., Peters, W., Dentener, F., and Krol, M.: Stability of tropospheric hydroxyl chemistry, J. Geophys. Res., 107(D23), 4715, doi:10.1029/2002JD002272, 2002.

Lelieveld, J., Brühl, C., Steil, B., Crutzen, P., Fischer, H., Giorgietta, M., Hoor, P., Milz, M., Sausen, R., Stiller, G., and Tost, H.: Stratospheric dryness: model simulations and satellite observations, Atmos. Chem. Phys., 7, 1313-1332, 2007, http://www.atmos-chem-phys.net/7/1313/2007/.

Lewis, A. C., Hopkins, J., Carpenter, L. J., Stanton, J., Read, K. A., and Pilling, M.: Sources and sinks of acetone, methanol, and acetaldehyde in North Atlantic marine air, Atmos. Chem. Phys., 5, 1963-1974, 2005, 
http://www.atmos-chem-phys.net/5/1963/2005/.

Logan, J. A.: Tropospheric ozone: Seasonal behavior, trends, and anthropogenic influence, J. Geophys. Res., 90, 10463-10482, 1985.

Logan, J. A., Prather, M. J., Wofsy, S. C., and McElroy, M. B.: Tropospheric chemistry: A global perspective, J. Geophys. Res., 86, 7210-7254, 1981.

Marandino, C., De Bruyn, W., Miller, S., Prather, M., and Saltzmann, E.: Oceanic uptake and the global atmospheric acetone budget, Geophys. Res. Lett., 32, L15806, doi:10.1029/2005GL023285, 2005.

McKeen, S. A., Gierczak, T., Burkholder, J. B., Wennberg, P. O., Hanisco, T. F., Keim, E. R., Gao, R.-S., Liu, S. C., Ravishankara, A. R., and Fahey, D. W.: The photochemistry of acetone in the upper troposphere: A source of odd-hydrogen radicals, Geophys. Res. Lett., 24, 3177-3180, 1997.

Moxley, J. M. and Cape, J. N.: Depletion of carbon monoxide from the nocturnal boundary layer, Atmos. Environ., 31, 1147-1155, 1997.

Müller, J.-F. and Brasseur, G.: IMAGES: A three-dimensional chemical transport model of the global troposphere, J. Geophys. Res., 100, 16445-16490, 1995.

Novelli, P. C., Masarie, K. A., and Lang, P. M.: Distribution and recent changes of carbon monoxide in the lower troposphere, $\mathrm{J}$. Geophys. Res., 103, 19015-19033, 1998.

Palmer, P. I., Jacob, D. J., Fiore, A. M., Martin, R. V., Chance, K., and Kurosu, T. P.: Mapping isoprene emissions over North America using formaldehyde column observations from space, J. Geophys. Res., 108, 4180, doi:10.1029/2002JD002153, 2003.

Park, R., Pickering, K., Allen, D., Stenchikov, G., and FoxRabinovitz, M.: Global simulation of tropospheric ozone using the University of Maryland Chemical Transport Model (UMDCTM): 1. Model description and evaluation, J. Geophys. Res., 109, D09301, doi:10.1029/2003JD004266, 2004a.

Park, R., Pickering, K., Allen, D., Stenchikov, G., and FoxRabinovitz, M.: Global simulation of tropospheric ozone using the University of Maryland Chemical Transport Model (UMDCTM): 2. Regional transport and chemistry over the central United States using a stretched grid, J. Geophys. Res., 109, D09303, doi:10.1029/2003JD004269, 2004b.

Pickering, K. E., Thompson, A. M., Wang, Y., Tao, W.-K., McNamara, E. P., Kichhoff, V. W. J. H., Heikes, B. G., Sachse, G. W., Bradshaw, J. D., Gregory, G. L., and Blake, D. R.: Convective transport of biomass burning emissions over Brazil during TRACE A, J. Geophys. Res., 101, 23 993-24 012, 1996.

Plass-Dülmer, C., Koppmann, R., Ratte, M., and Rudolph, J.: Light non-methane hydrocarbons in seawater, Global Biogeochem. Cycles, 9, 79-100, 1995.

Poisson, N., Kanakidou, M., and Crutzen, P. J.: Impact of nonmethane hydrocarbons on tropospheric chemistry and the oxidizing power of the global troposphere: 3-dimensional modelling results, J. Atmos. Chem., 36, 157-230, 2000.

Riedel, K., Allan, W., Weller, R., and Schrems, O.: Discrepancies between formaldehyde measurements and methane oxidation model predictions in the Antarctic troposphere: An assessment of other possible formaldehyde sources, J. Geophys. Res., 110, D15308, doi:10.1029/2005JD005859, 2005.

Roeckner, E., Brokopf, R., Esch, M., Giorgetta, M., Hagemann, S., Kornblueh, L., Manzini, E., Schlese, U., and Schulzweida,
U.: Sensitivity of simulated climate to horizontal and vertical resolution in the ECHAM5 atmosphere model, J. Climate, 19, 3771-3791, 2006.

Sander, R., Jöckel, P., Kerkweg, A., and Lelieveld, J.: Technical Note: The new comprehensive atmospheric chemistry module MECCA, Atmos. Chem. Phys., 5, 445-450, 2005, http://www.atmos-chem-phys.net/5/445/2005/.

Sanhueza, E., Dong, Y., Scharffe, D., Lobert, J. M., and Crutzen, P. J.: Carbon monoxide uptake by temperate forest soils: The effects of leaves and humus layers, Tellus, 50B, 51-58, 1998.

Seinfeld, J. H. and Pandis, S.: Atmospheric Chemistry and Physics: From Air Pollution to Climate Change, Wiley-Interscience, 1997.

Singh, H., Chen, Y., Tabazadeh, A., Fukui, Y., Bey, I., Yantosca, R., Jacob, D., Arnold, F., Wohlfrom, K., Atlas, D., Flocke, F., Blake, D., Blake, N., Heikes, B., Snow, J., Talbot, R., Gregory, G., Sachse, G., Vay, S., and Kondo, Y.: Distribution and fate of selected oxygenated organic species in the troposphere and lower stratosphere over the Atlantic, J. Geophys. Res., 105, 3795-3805, 2000.

Singh, H., Salas, 1., Chatfield, R., Czech, E., Fried, A., Walega, J., Evans, M., Field, B., Jacob, D., Blake, D., Heikes, B., Talbot, R., Sachse, G., Crawford, J., Avery, M., Sandholm, S., and Fuelberg, H.: Analysis of the atmospheric distriburion, sources, and sinks of oxygenated volatile orhanic chemicals based in measurements over the Pacific during TRACE-P, J. Geophys. Res., 105(D3), D15S07, doi:10.1029/2003JD003883, 2004.

Singh, H. B., Kanakidou, M., Crutzen, P. J., and Jacob, D. J.: High concentrations and photochemical fate of oxygenated hydrocarbons in the global troposphere, Nature, 378, 50-54, 1995.

Singh, H. B., Chen, Y., Staudt, A. C., Jacob, D. J., Blake, D. R., Heikes, B. G., and Snow, J.: Evidence from the Pacific troposphere for large global sources of oxygenated organic compounds, Nature, 410, 1078-1081, 2001.

Singh, H. B., Tabazadeh, A., Evans, M. J., Field, B. D., Jacob, D. J., Sachse, G., Crawford, J. H., Shetter, R., and Brune, W. H.: Oxygenated volatile organic chemicals in the oceans: Inferences and implications based on atmospheric observations and air-sea exchange models, Geophys. Res. Lett., 30, 1862, doi:10.1029/2003GL017933, 2003.

Solberg, S., Dye, C., Schmidbauer, N., Herzog, A., and Gehrig, R.: Carbonyls and nonmethane hydrocarbons at rural European sites from the Mediterranean to the Arctic, J. Atmos. Chem., 25, 33 66, 1996.

Spivakovsky, C. M., Logan, J. A., Montzka, S. A., Balkanski, Y. J., Foreman-Fowler, M., Jones, D. B. A., Horowitz, L. W., Fusco, A. C., Brenninkmeijer, C. A. M., Prather, M. J., Wofsy, S. C., and McElroy, M. B.: Three-dimensional climatological distribution of tropospheric $\mathrm{OH}$ : Update and evaluation, J. Geophys. Res., 105, 8931-8980, 2000.

Stickler, A., Fischer, H., Williams, J., de Reus, M., Sander, R., Lawrence, M., Crowley, J., and Lelieveld, J.: Influence of summertime deep convection on formaldehyde in the middle and upper troposphere over Europe, J. Geophys. Res., 111, D14308, doi:10.1029/2005JD007001, 2006.

Streets, D., Bond, T. C., Carmichael, G. R., Fernandes, S. D., Fu, Q., He, D., Klimont, Z., Nelson, S. M., Tsai, N. Y., Wang, M. Q., Woo, J. H., and Yarber, K. F.: An inventory of gaseous and primary aerosol emission in Asia in the year 2000, J. Geophys. Res., 
108(D21), 8809, doi:10.1029/2002JD003093, 2003.

Streets, D., Zhang, Q., Wang, L. He, K., Hao, J., Wu, Y., Tang, Y., and Carmichael, G.: Revisiting China's CO emissions after the Transport and Chemical Evolution over the Pacific (TRACE-P) mission: Synthesis of inventories, atmospheric modeling, and observations, J. Geophys. Res., 111, D14306, doi:10.1029/2006JD007118, 2006.

Taylor, K.: Summarizing multiple aspects of model performance in a single diagram, J. Geophys. Res., 106, 7183-7192, 2001.

Thompson, A.: The oxidizing capacity of the Earth's atmosphere: Probable past and future changes, Science, 256, 1157-1165, 1992.

Tie, X., Guenther, A., and Holland, E.: Biogenic methanol and its impacts on tropospheric oxydants, Geophys. Res. Lett., 17(17), 1881, doi:10.1029/2003GL017167, 2003.

Tost, H.: Global Modelling of Cloud, Convection and Precipitation Influences on Trace Gases and Aerosols, Ph.D. thesis, Rheinischen Friedrich-Wilhelms-Universität, Bonn, Germany, 2006.

Tost, H., Jöckel, P., Kerkweg, A., Sander, R., and Lelieveld, J.: Technical Note: A new comprehensive SCAVenging submodel for global atmospheric chemistry modelling, Atmos. Chem. Phys., 6, 565-574, 2006a.

Tost, H., Jöckel, P., and Lelieveld, J.: Influence of different convection parameterisations in a GCM, Atmos. Chem. Phys., 6, 54755493, 2006b.

Vakhtin, A., Murphy, J., and Leone, S.: Low-Temperature Kinetics of Reactions of $\mathrm{OH}$ Radical with Ethene, Propene, and 1-Butene, J. Phys. Chem., 107, 10 055-10 062, 2003.

van Aardenne, J., Dentener, F., Olivier, J., Peters, J., and Ganzeveld, L.: The EDGAR 3.2 Fast Track 2000 dataset (32FT2000), http://www.mnp.nl/edgar/model/v32ft2000edgar/ docv32ft2000/, 2005.

von Kuhlmann, R., Lawrence, M. G., Crutzen, P. J., and Rasch, P. J.: A model for studies of tropospheric ozone and nonmethane hydrocarbons: Model description and ozone results, J. Geophys. Res., 108, 4294, doi:10.1029/2002JD002893, 2003a.

von Kuhlmann, R., Lawrence, M. G., Crutzen, P. J., and Rasch, P. J.: A Model for Studies of Tropospheric Ozone and Non-Methane Hydrocarbons: Model Evaluation of Ozone Related Species, J. Geophys. Res., 108, 4729, doi:10.1029/2002JD003348, 2003 b. von Kuhlmann, R., Lawrence, M. G., Pöschl, U., and Crutzen, P. J.: Sensitivities in global scale modeling of isoprene, Atmos. Chem. Phys., 4, 1-17, 2004, http://www.atmos-chem-phys.net/4/1/2004/.

Wang, X., McElroy, M., Wang, T., and Palmer, P.: Asian emission of $\mathrm{CO}$ and $\mathrm{NO}_{\mathrm{x}}$ : Constrain from aircraft and Chinese station data, J. Geophys. Res., 109, D24304, doi:10.1029/2004JD005250, 2004.

Wang, Y. and Zeng, T.: On tracer correlations in the troposphere: The case of ethane and propane, J. Geophys. Res., 109, D24306, doi:10.1029/2004JD005023, 2004.

Wang, Y., Jacob, D. J., and Logan, J. A.: Global simulation of tropospheric $\mathrm{O}_{3}-\mathrm{NO}_{x}$-hydrocarbon chemistry, 1. Model formulation, J. Geophys. Res., 103, 10713-10 725, 1998a.

Wang, Y., Logan, J. A., and Jacob, D. J.: Global simulation of tropospheric $\mathrm{O}_{3}-\mathrm{NO}_{\mathrm{x}}$-hydrocarbon chemistry, 2. Model evaluation and global ozone budget, J. Geophys. Res., 103, 10 727-10 755, 1998b.

Wennberg, P. O., Hanisco, T. F., Jaeglé, L., Jacob, D., Hintsa, E. J., Lanzendorf, E. J., Anderson, J. G., Gao, R.-S., Keim, E. R., Donnelly, S. G., Negro, L. A. D., Fahey, D. W., McKeen, S. A., Salawitch, R. J., Webster, C. R., May, R. D., Herman, R. L., Proffitt, M. H., Margitan, J. J., Atlas, E. L., Schauffler, S. M., Flocke, F., McElroy, C. T., and Bui, T. P.: Hydrogen radicals, nitrogen radicals, and the production of $\mathrm{O}_{3}$ in the upper troposphere, Sci. China, 279, 49-53, 1998.

Williams, J., Pöschl, U., Crutzen, P. J., Hansel, A., Holzinger, R., Warneke, C., Lindinger, W., and Lelieveld, J.: An atmospheric chemistry interpretation of mass scans obtained from a proton transfer mass spectrometer flown over the tropical rainforest of Surinam, J. Atmos. Chem., 38, 133-166, 2001.

Zhou, X. and Mopper, K.: Photochemical production of lowmolecular weight compounds in seawater and surface microlayer and their air-sea exchange, Mar. Chem., 56, 201-213, 1997. 